\title{
TESTING FOR ASYMMETRIC INFORMATION IN PRIVATE HEALTH
}

\section{INSURANCE*}

Pau Olivella and Marcos Vera-Hernández

\section{[For the typesetter: Short form of the title for use as a pagehead in the Journal: ASYMMETRIC INFORMATION IN HEALTH INSURANCE]}

We test for asymmetric information in the UK private health insurance (PHI) market. In contrast to earlier research that considers either a purely private system or one where private insurance is complementary to public insurance, PHI is substitutive of the public system in the UK. Using a theoretical model of competition among insurers incorporating this characteristic, we link the type of selection (adverse or propitious) with the existence of risk-related information asymmetries. Using the British Household Panel Survey, we find evidence that adverse selection is present in the PHI market, which leads us to conclude that such information asymmetries exist.

The extent to which individuals have privileged information on their own risks (ex-ante asymmetric information) is important because it is one of the main justifications for public intervention in insurance markets (Dahlby, 1981). Indeed, individuals who know that their risk of falling ill is low will have a low willingness to pay for health insurance. This might lead to the well-known problem of adverse selection, which results in lower risk individuals enjoying less than full insurance.

Corresponding author: Pau Olivella, Department of Economics, Universitat Autónoma de Barcelona, 08193 Bellaterra, Spain. Email: pau.olivella@uab.es.

We are indebted to Phillips Blackburn, Erin Flood, Charlie McEwan, and Simon Moody for their contribution to our understanding of the private health insurance market in the UK. We are grateful for useful comments from Jörn-Steffen Pischke (Editor), and three anonymous referees, as well as Jerome Adda, James Bank, Sami Berlinski, Richard Blundell, Simon Burgess, Winnand Emmons, Emla Fitzsimons, Izabela Jelovac, Jonas Kinge, Matilde Machado, Inés Macho-Stadler, Judith Payne, Carol Propper, Lise Rochaix-Ranson, Bernard Salanié, and other participants at seminars in Bristol, UCL, Imperial, City, Oslo, Chicago, Barcelona, and Ankara. All remaining errors are our sole responsibility. Vera-Hernández acknowledges support from the ESRC Centre for the Microeconomic Analysis of Public Policy (RES-54428-0001). Olivella acknowledges the support of the Barcelona Graduate School of Economics and of the Government of Catalonia, project 2009SGR-169; as well as from the Ministerio de Educación y Ciencia, project ECO2009-07616 and CONSOLIDER-INGENIO CSD2006-16. Olivella is a Research Fellow of MOVE and Barcelona GSE. 
The main aim of this work is to test for asymmetric information in the UK's private health insurance (PHI) market. Unlike previous literature, we focus on a market that coexists with a free public and universal outside option, namely, the National Health Service (NHS). Indeed, everyone is publicly insured under the NHS, which is funded through taxation. So individuals contribute to the financing of public care, whether they use it or not (Propper, 1989,1993; Besley and Coate, 1991; OECD, 2004). The presence of a free public outside option, the NHS, means that we cannot directly apply the results of the standard Rothschild and Stiglitz (1976) (RS henceforth) model to build our test. The reason is that no such outside option exists in their analysis. Hence, our theoretical analysis contributes to the existing literature by incorporating a public insurer as an outside option within a RS framework. ${ }^{1}$

Our strategy to test for asymmetric information is built in two steps. In the first step, using a theoretical model, we show that if information is symmetric (asymmetric) then propitious (adverse) selection should be observed. This contrasts with the standard RS framework which predicts the absence of any selection under symmetric information (that is, both high risk and low risk individuals end up enjoying full insurance).

In the second step, we use the British Household Panel Survey (University of Essex, 2010) to ascertain whether selection is adverse or propitious. Our test compares the use of health care services by employees who receive PHI as a fringe benefit with that by individuals who buy it directly. Individually bought PHI and employer PHI provide similar benefits in the UK (Propper and Maynard, 1989), a conclusion that our empirical analysis corroborates. Hence, any difference in the use of health care services between the two groups is due to differences in risk, and not to differences in the levels of coverage (the so-called price or moral hazard effect). We find evidence of adverse selection. Individuals

\footnotetext{
${ }^{1}$ This is a contribution of our work because the competitive equilibrium that arises within such a framework has, to our knowledge, never been studied under either symmetric or asymmetric information. An exception is Encinosa (2003), but he concentrates on the case in which the PHI market offers a single (and therefore pooling) contract. On the other hand, he extends the analysis to heterogeneous income. Previous literature has focused either on a framework in which the PHI covers whatever copayments are not covered by a basic public insurance contract, or on one in which the public insurance is altogether absent. More on this below.
} 
who purchase PHI have a higher probability of both hospitalisation and visiting their general practitioner (GP) than individuals who receive PHI as a fringe benefit. This leads us to conclude that asymmetric information is present in the PHI market in the UK.

As for our testing strategy, it is subject to three different potential sources of bias, which we investigate and are able rule out. First, differences in health care use might reflect differences in health between those with employer-provided PHI and those without. Second, employers that provide PHI might also facilitate the take-up of preventive services, which might translate into lower use of curative health care for individuals with employer-provided PHI. Third, these differences in hospitalisation rates could also be caused by differences in the coverage made available between employer-provided PHI and individually purchased PHI.

The empirical literature has found mixed evidence on whether there is any selection in insurance markets, which casts doubts on the existence of asymmetric information and on the need for public intervention. On the one hand, in his survey of insurance markets, Chiappori (2000) concludes that the importance of adverse selection is limited. Nor do Cardon and Hendel (2001) find evidence of adverse selection in the US employerprovided health insurance market. Chiappori and Salanié (1997, 2000) find no evidence of adverse selection in the French automobile insurance market. In the life insurance market, neither Cawley and Philipson (1999) nor Hendel and Lizzeri (2003) find evidence of adverse selection. On the other hand, Ettner (1997) and Finkelstein (2004) find evidence of adverse selection in the Medigap market in the US. Finkelstein and Poterba (2004, 2006) find evidence of adverse selection in the UK annuity market, and Finkelstein and McGarry (2006) find evidence of risk-related adverse selection in the US long-term care insurance market. More recently, Fang et al. (2008) find evidence of propitious selection in the Medigap market. It is clear that more research is needed in order to obtain a better assessment of the presence of asymmetric information in insurance markets.

Around the world, public and private health insurance are linked in different ways. In the US, a large segment of the population is ineligible for public insurance and must 
resort to PHI. For this segment of the population, their situation constitutes an example of a purely private framework. In France, Belgium, and the US Medicare, PHI is complementary to public insurance: an individual obtains a basic insurance contract from the insurer of his choice (funded by the government) and can buy a complementary PHI contract to cover whatever copayments are not covered by the basic insurance contract. We refer to this as the 'complements framework'.

In the UK, our testing arena, the public insurance system provides treatment instead of just financing some basic coverage. Hence, an individual can only substitute the treatment funded by the public system by receiving care funded through PHI. This means that the private insurer must bear the entire treatment cost. We refer to this as the 'substitutes framework', which is not only found in the UK but also in Finland, Greece, Italy, Mexico, New Zealand, Portugal, and Spain. ${ }^{2}$

It may seem puzzling, in systems with a publicly funded outside option, that anyone would purchase PHI in the first place. A possible explanation is that private care is perceived to be of higher quality along some dimension (Besley and Coate, 1991). For instance, PHI enrollees are able to obtain treatment from the private sector without having to put up with long waiting lists (Propper and Maynard, 1989; Propper, 1995; Besley et al., 1998 and 1999; Propper et al., 2001; OECD, 2004). Another possible reason is that health care obtained through PHI offers better hotel services.

Our paper is organised as follows. In Section 1 we present our model of a substitutes framework and provide our equilibrium notion. In Section 2 we solve the model both under symmetric information (subsection 2.1) and under asymmetric information (subsection 2.2) and perform some comparisons (subsection 2.3). Also in Section 2, we discuss our results when we extend the model to consider heterogeneity in other dimensions (subsection 2.4), and we compare the predictions of the substitutes and the complements framework (subsection 2.5). In Section 3 we perform the empirical analysis. We first describe the institutional setting (subsection 3.1) and the data (subsection 3.2), then explain

\footnotetext{
${ }^{2}$ See OECD (2004) for a proposal of taxonomy of health insurance with country examples. The authors use the term 'duplicate' to refer to what we call the substitutes system.
} 
the test in detail (subsection 3.3) and report our main results (subsection 3.4). We then investigate the source of asymmetric information (subsection 3.5). We finish section 3 by discussing three potential threats to the validity of our results and showing why they are not relevant in our setting (subsection 3.6). We conclude the paper in Section 4. In an online Technical Appendix we have relegated some mathematical derivations (section A), the proofs of all lemmata and propositions (Section B), some additional tables (Section $\mathrm{C})$, and the extension of the model to the case of endogenous taxes (Section D).

\section{A Model of a Substitutes Framework}

A substitutive PHI is characterised by the following two features. First, if an individual with PHI seeks care, he must choose between the private treatment covered by his insurance ('the private option') and the publicly funded treatment ('the public option'). That is, privately and publicly funded services cannot be combined (e.g., he cannot have an operation in the public option and then receive its post-operative treatment in the private option). Second, when an individual with PHI chooses the private option, the private insurer must bear the full cost of treatment. Our theoretical model considers these two distinguishing features of the substitutes framework.

Insurers use some observables to classify individuals and tailor their contract offer to each specific class. Within a class, all individuals face the same loss $\ell_{0}$ upon perceiving the need of seeking care and enjoy the same net (post-tax) income $w{ }^{3}$ All heterogeneity among individuals within a class comes from their innate probability of seeking health care (see subsection 2.4 for a discussion on the consequences of having also risk aversion or loss size heterogeneity). By innate we mean that differences in this probability across individuals can either relate to differences in health status or differences in the individuals' preferences for health care, but they do not incorporate the effects of differences in access conditions. As mentioned in the introduction, our empirical analysis sheds some light on the true source of heterogeneity.

\footnotetext{
${ }^{3}$ The main results are robust to the introduction of taxes (see section $\mathrm{D}$ of the online Technical Appendix for a model with endogenous taxes).
} 
We assume that there are high risk and low risk individuals. Let $p_{H}$ (respectively, $p_{L}$ ) be the innate probability of seeking care of the high risk (low risk) individuals, $0<p_{L}<p_{H}<1$. Under symmetric information, the individual's innate probability of seeking care is publicly observable, while it is only observed by him under asymmetric information. We analyse both cases. It is common knowledge that the proportion of low risks in the economy is $0<\gamma<1$. We denote by $\bar{p}=\gamma p_{L}+(1-\gamma) p_{H}$ the average innate probability of seeking care in the population.

If an individual has chosen to purchase PHI from a specific insurer, he enjoys double coverage. If this individual seeks care, he chooses either the public or the private option. Each of these two options may imply different copayments, waiting times, qualities, ancillary services, or guidelines. We will measure all of these characteristics, as well as the initial health status, in monetary units, as is standard in models of insurance under asymmetric information. Let $a$ be the final disposable income in the case of seeking care and let $n$ be that in the case of not seeking health care. An individual of type $J=L, H$ enjoys ex-ante expected utility given by

$$
U^{J}(n, a)=p_{J} u(a)+\left(1-p_{J}\right) u(n) .
$$

If an individual obtains treatment from the public option (either because he has not purchased PHI or because he prefers the public treatment), his loss is reduced from $\ell_{0}$ to $\ell_{P U B}$. Suppose that he is of type $J$. If he has decided not to purchase PHI, he enjoys expected utility $U^{J}\left(w, w-\ell_{P U B}\right)$. PHI contracts are available in the market and can be described by a two-dimensional vector $(\ell, q)$, where $\ell$ denotes the insurer's commitment to reduce the insuree's final losses from $\ell_{0}$ to $\ell$ if he seeks privately funded treatment and $q$ denotes the insurance premium. Therefore, if the individual of type $J$ does purchase some private contract $(\ell, q)$, his expected utility is $U^{J}(w-q, w-\ell-q){ }^{4}$ An insurer

\footnotetext{
${ }^{4} \mathrm{An}$ implicit assumption is that an agent does not receive a tax rebate if he chooses to purchase private insurance. Otherwise, the government would return part of the taxes paid by this consumer and $w$ would have to be revised accordingly. In the UK (our testing arena), a rebate was in place for individuals over the age of 60 but it was discontinued in July 1997.
} 
offering contract $(\ell, q)$ bears the cost of reducing losses from $\ell_{0}$ to $\ell$. Expected profits are therefore given by $q-p_{J}\left(\ell_{0}-\ell\right)$.

After conducting the standard change of variable (see subsection A.1 of the online Technical Appendix for details), in Figure 1 we depict indifference curves, zero isoprofits, and contracts in the space of final wealths. It is important to notice that, whereas the zero isoprofit lines go through the point of no insurance (neither public nor private), denoted by $\mathbf{A}$, the final wealth vector associated with the public option (denoted by $\mathbf{P}$ ) is any point in the vertical line through $n=w$. Allocative efficiency is reached at contracts on the 45-degree line, where isoprofits and indifference curves are tangent. If on top of efficiency we impose zero profits per type, we obtain the contracts labelled $\boldsymbol{\alpha}_{L}^{*}$ and $\boldsymbol{\alpha}_{H}^{*}$ in the figure. These contracts will become useful later on.

\section{[FIGURE 1 AROUND HERE]}

The presence of the public option $\mathbf{P}$ at the outset (i.e. constituting a committed offer) may imply that some contracts that were attracting individuals in the equilibrium in the absence of $\mathbf{P}$ may now become inviable, and vice versa. Hence the following terminology.

DEFINITION 1. If a contract $\alpha$ attracts some individuals, we say that the contract is active. Analogously, if the public option attracts some individuals, we say that the public sector is active.

A sufficient condition for a contract to be active in equilibrium is that it offers strictly more utility to some risk type than both the rest of the contracts offered and the public option. The same goes for the public option. However, this condition is not necessary. If some type is indifferent between two offers, both offers may attract individuals of this type. The simplest way to close the model is to assume the following tie-breaking rule.

Assumption 1. If all individuals of type $J$ are indifferent between the public option $\mathbf{P}$ and the best private contract for them, all individuals of type $J$ choose the public option.

Our equilibrium notion is the following. 
Definition 2. An equilibrium set of active contracts $\mathbf{S}$ (ESAC henceforth) is a set of contracts (that may or may not include the public option $\mathbf{P}$ ) such that

(i) each and every contract in $\mathbf{S}$ is offered either by some insurer(s) or by the public sector and is active; and

(ii) if a single insurer deviates by offering a contract outside this set, either this contract will be inactive or this insurer will not make additional profits.

\section{Solving the Model for each Informational Scenario}

We first solve the game under the hypothesis of symmetric information. We then proceed to the case where the innate probability of seeking care is an individual's private information. After comparing the equilibria in the two settings, we move to some extensions. Finally, we look at differences between the substitutes and the complements frameworks.

\subsection{The Equilibrium under Symmetric Information}

Consider first the situation in which there is no public health option. The low and high risk PHI markets are segmented. Following RS, the equilibrium entails efficient contracts (full insurance) and zero profit per individual, no matter his type. This yields contracts $\left\{\boldsymbol{\alpha}_{H}^{*}, \boldsymbol{\alpha}_{L}^{*}\right\}$ depicted in Figure 1 (see subsection A.2 of the online Technical Appendix for details).

We now find the ESAC for each possible $\mathbf{P}$ (that is, for each possible value of $\ell_{P U B}$ ). We illustrate our arguments by means of Figure 1. Point $\mathbf{H}_{0}$ is the public option such that a high risk is indifferent between $\boldsymbol{\alpha}_{H}^{*}$ and $\mathbf{H}_{0}$. Point $\mathbf{L}_{0}$ is the public option such that a low risk is indifferent between $\boldsymbol{\alpha}_{L}^{*}$ and $\mathbf{L}_{0}$. The following lemma cannot be proven graphically and is a consequence of Jensen's inequality. ${ }^{5}$

LEMMA 1. If individuals only differ in their innate probability of seeking care, point $\mathbf{H}_{0}$ lies below point $\mathbf{L}_{0}$.

\footnotetext{
${ }^{5}$ We are indebted to Juan Enrique Martínez-Legaz for providing the elegant proof that can be found in section B of the online Technical Appendix.
} 
This result is the cornerstone of our empirical test. Before providing the intuition, let us point out that the limited heterogeneity assumption is sufficient but not necessary, as will be shown in subsection 2.4 , where we discuss the possibility that individuals also differ in their attitude toward risk as well as in the size of their loss.

The intuition for Lemma 1 is the following. In the competitive equilibrium under symmetric information, each type opting for PHI pays an actuarially fair contract covering his losses in full in the case of seeking care. Therefore, the premium paid by a high risk is higher than that of the low risk, while the coverage is the same. At the point of deciding whether to purchase PHI or not, an individual is confronted with the possibility of a free outside option (the public sector services) that only offers partial coverage (perhaps due to long waiting, low-quality amenities, and so on). Graphically, the public option is far from the 45-degree line. Since the high risks pay a higher premium for PHI, they would be indifferent between PHI and the public sector even if the coverage in the public sector were relatively low. Hence the point $\mathbf{H}_{0}$ is relatively low. Consider now the low risks. They pay a low premium. If they are as risk averse as the high risks and if they face the same loss as the high risks, then the coverage in the public sector needed to make them indifferent between sectors has to be high. Hence point $\mathbf{L}_{0}$ is high.

Notice, however, that if the low risks where sufficiently less risk averse than the high risks, then the public sector coverage that would make them indifferent between sectors would be so small that point $\mathbf{L}_{0}$ might lie below $\mathbf{H}_{0}$. We discuss this possibility in subsection 2.4.2. A similar conclusion would be reached if the loss faced by a low risk were sufficiently smaller than a high risks' loss. We discuss this other possibility in subsection 2.4.3.

Once the positions of $\mathbf{H}_{0}$ and $\mathbf{L}_{0}$ are known, we can analyse the situation case by case, i.e., for each possible position of the public option.

Proposition 1. Suppose that information is symmetric. Then, under Assumption 1, a unique ESAC exists for each and every position of the public option $\mathbf{P}$, and it is characterised as follows. 
(a) If $\mathbf{P}$ lies strictly below point $\mathbf{H}_{0}$, the ESAC is $\left\{\boldsymbol{\alpha}_{L}^{*}, \boldsymbol{\alpha}_{H}^{*}\right\}$, high risks pick $\boldsymbol{\alpha}_{H}^{*}$ and low risks pick $\boldsymbol{\alpha}_{L}^{*}$; the public sector is inactive.

(b) If $\mathbf{P}$ lies on or above point $\mathbf{H}_{0}$ but strictly below point $\mathbf{L}_{0}$, the $E S A C$ is $\left\{\boldsymbol{\alpha}_{L}^{*}, \mathbf{P}\right\}$, low risks pick $\boldsymbol{\alpha}_{L}^{*}$ and high risks pick $\mathbf{P}$; both sectors are active.

(c) If $\mathbf{P}$ lies on or above $\mathbf{L}_{0}$, the ESAC is $\{\mathbf{P}\}$ and only the public sector is active.

Notice that both sectors are active only if (b) holds, and in this case only the low risks resort to the private sector. This yields the following corollary.

Corollary 1. Suppose that the two sectors are active and information is symmetric. Under Assumption 1, the innate probability of seeking care among the privately insured is $p_{L}$, which is smaller than $\bar{p}$, the average in the general population.

The reason we compare the innate probability of seeking care of those who purchase insurance with the average probability in the general population will be explained in Section 3 , since it is relevant for our empirical test.

The intuition for this result is the following. Under symmetric information, the only possible way to survive competition is to offer full insurance. Since all individuals face the same loss irrespective of their risk, ${ }^{6}$ this means that the premium should be larger for the high risk market than for the low risk market. If public health insurance is available and is financed with compulsory general taxation, it will be more attractive to a high risk because he would have to pay a larger premium to private insurers.

Finally, notice that we are not saying that the only possible prediction of our model under symmetric information is that adverse selection into PHI will be observed. Our claim is that, if information is symmetric and both options are active then propitious selection should be observed.

\subsection{The Equilibrium under Asymmetric Information}

As in the previous subsection, consider first the situation where there is no public health system. We know from RS that the competitive equilibrium, if it exists, entails

\footnotetext{
${ }^{6} \mathrm{We}$ will discuss the consequences of relaxing this assumption in subsection 2.4.3.
} 
an efficient contract (full insurance) for the high risks and zero profits for an insurer attracting a high risk. Therefore, the high risk contract under asymmetric information is the same as under symmetric information, $\boldsymbol{\alpha}_{H}^{*}$. The low risk contract must satisfy the high risk incentive compatibility constraint with equality and also yield zero profits. These two equations yield the contract depicted by $\hat{\boldsymbol{\alpha}}_{L}$ in Figure 2 (the roman numerals can be ignored as they are just used in the proofs). ${ }^{7}$

\section{[FIGURE 2 AROUND HERE]}

In Figure 2, point $\mathbf{H}_{0}$ is again the public contract such that a high risk is indifferent between $\boldsymbol{\alpha}_{H}^{*}$ and $\mathbf{H}_{0}$. Notice that point $\mathbf{H}_{0}$ is the same whether information is present or not, since the equilibrium contract for the high risk is the same. Point $\mathbf{L}_{1}$ is the public contract such that a low risk is indifferent between $\hat{\boldsymbol{\alpha}}_{L}$ and $\mathbf{L}_{1}$. The relative position of $\mathbf{H}_{0}$ and $\mathbf{L}_{1}$ is given in the next lemma.

LEMMA 2. If individuals only differ in their innate probability of seeking care, $\mathbf{H}_{0}$ lies above $\mathbf{L}_{1}$.

Intuitively, asymmetric information forces the market to offer such a low coverage to the low risk, that the coverage needed in the public option to induce indifference between sectors is also very small.

The next proposition characterizes the ESAC for each possible position of $\mathbf{P}$ in Figure 2.

Proposition 2. Suppose that information is asymmetric. Then, under Assumption 1, a unique ESAC exists for each and every position of the public option $\mathbf{P}$, and is characterised as follows.

(a) If $\mathbf{P}$ lies strictly below point $\mathbf{L}_{1}$, the ESAC is $\left\{\hat{\boldsymbol{\alpha}}_{L}, \boldsymbol{\alpha}_{H}^{*}\right\}$; high risks pick $\boldsymbol{\alpha}_{H}^{*}$ and low risks pick $\hat{\boldsymbol{\alpha}}_{L}$; the public sector is inactive.

\footnotetext{
${ }^{7} \mathrm{As}$ is well known, the set of contracts $\left\{\hat{\boldsymbol{\alpha}}_{\boldsymbol{L}}, \boldsymbol{\alpha}_{\boldsymbol{H}}^{*}\right\}$ constitutes only a candidate, albeit unique, for a competitive equilibrium. In the purely private competitive model there exists a critical proportion of low risks such that an equilibrium exists if and only if this critical value is not exceeded. This is our working assumption here on.
} 
(b) If $\mathbf{P}$ lies on or above point $\mathbf{L}_{1}$ but strictly below point $\mathbf{H}_{0}$, the ESAC is $\left\{\boldsymbol{\alpha}_{H}^{*}, \mathbf{P}\right\}$; low risks pick $\mathbf{P}$ and high risks pick $\boldsymbol{\alpha}_{H}^{*}$; both sectors are active.

(c) If $\mathbf{P}$ lies on or above point $\mathbf{H}_{0}$, the ESAC is $\{\mathbf{P}\}$ and only the public sector is active.

Notice that both sectors are active only in case (b), where the high risks pick the private sector. We have the following and most important corollary.

Corollary 2. Suppose that the two sectors are active and information is asymmetric. Then, under Assumption 1, the innate probability of seeking care for those who decide to purchase private insurance is $p_{H}$, which is larger than $\bar{p}$, the average in the general population.

The intuition for this result is the following. Regarding why the private option can only be in equilibrium if it offers full insurance to the high risks, the same intuition of the RS model applies, namely, that competitive forces will rule out any inefficiencies or positive profits in the contract of the type that has most incentives to lie. Let us suppose now that the private option supports a contract aimed at attracting the low risks. Again due to competitive forces, such a contract could not yield positive profits. More importantly, it would have to provide (much) less than full insurance at a cheap premium, in order to avoid high risks disguising themselves as low risks. Notice that this implies that the private option would do a very poor job in terms of insurance. If the public option is to be active, as assumed, it must be because it attracts these low risks. Let us stress that our claim is conditional on both sectors being active.

\subsection{Comparisons}

Corollaries 1 and 2 tell us that the sign of the difference between $\bar{p}$ and the innate probability of seeking care of the privately insured crucially depends on whether information is symmetric or asymmetric. Basically, symmetric information leads to propitious selection, while asymmetric information leads to adverse selection. This is the main contribution of our theoretical model, as it leads us to conclude that any evidence on adverse 
selection is also indirect evidence of asymmetric information. Hence the relevance of the test performed in the next section.

\subsection{Extensions}

Let us discuss under which conditions our main theoretical result extends to some alternative scenarios. In particular, we address the possibility that relevant information on individuals has more than one dimension, an issue that has received a great deal of attention lately. Indeed, it is plausible that individuals differ not only in their underlying innate probability of seeking care but also in other attributes such as their intrinsic costs of waiting (relevant when waiting time is higher in the public system than in the private system), their attitude towards risk, or the severity of their illness in the case of falling ill.

\subsubsection{Heterogeneous waiting costs}

As explained in the introduction, one of the motivations for purchasing $\mathrm{PHI}$ in the UK is to circumvent long waiting lists in the NHS (no, or very short, waiting exists in the PHI sector). Hence, individuals with larger waiting costs (possibly individuals with higher wages) will be more inclined to buy PHI. It is fair to ask whether our one-to-one relationship between the informational assumption and the sign of selection (adverse or propitious) extends to a model where individuals also differ in the costs of being treated in the NHS. More specifically, we address the situation where the loss in the public option $\left(\ell_{P U B}\right)$ is in part determined by waiting time. It is natural to assume that high-wage individuals' forgone income while waiting for treatment could be larger than that of lowwage individuals. It is then clear that if insurers cannot condition their contracts on income, the high-wage individuals will purchase PHI, which would go in the direction of propitious selection because high-wage individuals are usually healthier. If this effect is strong enough, it could be the case that one observes propitious selection even in the presence of asymmetric information on medical risk.

More harmful to our (indirect) test for asymmetric information would be the possib- 
ility that the sign of our results is reversed under symmetric information. However, notice that waiting cost heterogeneity, according to the previous argument, can only decrease adverse selection. Hence, if anything, observing adverse selection could only be underestimating the extent of asymmetric information. We must acknowledge, nevertheless, that the implication is less clear if the heterogeneity in the innate probability of seeking care is due to differences in prefrences for helath (e.g., the importance given to health by the individual), rather than health status.

\subsubsection{Heterogeneous risk preferences}

Suppose that individuals differ in risk preferences as well as in risk. ${ }^{8}$ In consequence, indifference curves differ (at any fixed contract) not only in their slope (low risks have steeper indifference curves) but also in their curvature (more risk averse individuals have more curved indifference curves). In Figure 3 we depict the worst scenario for the validity of our test, that is, one in which symmetric information might also lead to adverse selection, as we would then be interpreting evidence of adverse selection as a sign of asymmetric information when in fact information is symmetric. In the figure we represent two types of individual. Type $H H$ individuals have a high innate probability of seeking care and are very risk averse. Type $L L$ individuals have a low innate probability and are more risk tolerant. Notice that this reflects the caveat expressed after Lemma 1. Under symmetric information, both types should receive full insurance and actuarially fair contracts: contracts $\boldsymbol{\alpha}_{L}^{*}$ and $\boldsymbol{\alpha}_{H}^{*}$ in the figure, where subindices refer to risk only, not to risk preference. Given these contracts, $H H$ individuals facing a public outside option in the vertical line through $\mathbf{A}$ and between $\mathbf{H H}_{0}$ and $\mathbf{L} \mathbf{L}_{0}$ in the figure will prefer the private system, while $L L$ individuals facing this same public option will prefer the public to the private system. Thus adverse selection is observed if one restricts attention to $H H$ and $L L$ individuals.

\section{[FIGURE 3 AROUND HERE]}

\footnotetext{
${ }^{8} \mathrm{~A}$ similar analysis applies when individuals differ in their initial wealth, as their risk aversion is affected by initial wealth. However, it is well known (see, for instance, Rees and Wambach, 2008, Chapter 2.3) that under (empirically plausible) decreasing absolute risk aversion, richer individuals will, everything else equal, show a lower willingness to pay for insurance, which seems to run against evidence. A possible explanation for this apparent paradox is explored in the previous subsection.
} 
However, notice two things. First of all, for the $H H$ and the $L L$ indifference curves to cross to the left of the vertical line through $\mathbf{A}$, as depicted, one needs that the $L L$ type has a sufficiently lower risk aversion than the $H H$ type. We formalise this point next, a generalisation of Lemma 1.

LEMma 3. Suppose that type LL values final wealth according to utility function $u_{L}$ and that type $H H$ does so according to utility function $u_{H}$. Suppose further that $\left|u_{H}(z)-u_{L}(z)\right|$ is sufficiently close to zero for all $z$. Then point $\mathbf{H H}_{0}$ lies below point $\mathbf{L L}_{0}$.

Second, types $L H$ and $H L$ also exist. For these types, the conclusions reached in the main analysis are reinforced. Indeed, under symmetric information, $H L$ individuals have an additional reason to stay out of the private system: not only is their premium high, but also they have a low willingness to pay for insurance. Type $L H$ individuals, on the other hand, will purchase PHI not only because their premium is low but also because they are very risk averse. This discussion points to propitious selection into the PHI sector.

To sum up, in order to have adverse selection into PHI under symmetric information, three conditions have to hold simultaneously: (i) differences in risk aversion among individuals are large enough; (ii) the public option offers a coverage consistent with placing $\mathbf{P}$ exactly inside the interval given by $\mathbf{H H}_{0}$ and $\mathbf{L L}_{0}$ in Figure 3, which is narrower than the interval that ensures that both sectors are active $;^{9}$ and (iii) the correlation between risk and risk aversion is non-negative, i.e., individuals with a high innate probability of seeking care should also have an underlying dislike of risk. As for (iii), Cutler et al. (2008) find that for Medigap and for acute health insurance there is no systematic relationship between expected claims and behaviour measures that reflects risk attitudes. ${ }^{10}$ Finally,

\footnotetext{
${ }^{9}$ In our base model, that $\mathbf{P}$ lies in the interval ensuring that both sectors are active, necessarily implies that Lemma 1 applies. Here, instead, even if both sectors are active this does not imply that $\mathbf{P}$ lies between points $\mathbf{L L}_{0}$ and $\mathbf{H H}_{0}$. Indeed, it could be the case that $\mathbf{P}$ lies between $\mathbf{H L}_{0}$ and $\mathbf{L} \mathbf{L}_{0}$, in which case all low risks, regardless of their risk preference, would purchase PHI (and also the high risks that have high risk aversion), while the relatively risk-tolerant high risks would resort to the public option. Hence propitious selection into PHI would be observed.

${ }^{10}$ Finkelstein and McGarry (2006) find that risk aversion and risk are positively correlated, but this is specifically for the long-term care insurance market rather than for the health insurance market which is
} 
if uptake of preventive behaviour is positively correlated with risk aversion and preventive behaviour reduces the innate probability of seeking health care, then our results are reinforced.

What are the consequences of introducing risk preference heterogeneity when information is asymmetric? Here we enter much less trodden terrain: the equilibrium in a competitive market with multidimensional private information. Very few authors have addressed this situation even in the absence of the public option. ${ }^{11}$ Smart (2000) shows that coverage always goes in the same direction as risk, so that the viability of a private contract aimed at low risks in the presence of a free outside option is always more problematic than the viability of a private contract aimed at high risks. This suggests that the presence of a free outside option would have a similar effect to that in our model.

\subsubsection{Heterogeneous severity of illness}

A model in which individuals are heterogeneous in the severity of illness (as well as in the probability of seeking care) is much further away from our base model. First, one would expect the public sector to step in and prioritise the most severe cases, so public coverage would become type-dependent. Second, the issue of whether private coverage could also be contingent on the size of loss becomes important, and results will depend on the degree of flexibility that private insurers have in tailoring coverage as a function of loss. ${ }^{12}$

Let us nevertheless point to some graphical intuitions for the simple case where: (i) considered in Cutler et al. (2008).

${ }^{11}$ See Wambach (2000), Villeneuve (2003), and Smart (2000). In addition, these authors assume that each insurer is restricted to offer a single contract. The consequences of allowing firms to offer menus of contracts remains an open question.

${ }^{12}$ See Selden $(1993,1997)$ and Blomqvist and Johansson (1997a, 1997b), who study a model where individuals differ in the severity of their illness once ill. However, there is no heterogeneity at the time of purchasing insurance in their models, since (i) individuals choose the amount of insurance before they learn the severity of their illness, and (ii) the probability distribution over severity is the same for all individuals. On the other hand, their model of consumers' preferences and behaviour is richer - preferences are defined on both health and non-health goods, and consumers are allowed to contract further health services after becoming ill. Encinosa (2003) studies a model where individuals differ in their valuation of health services, which could also be interpreted as differences in severity. However, as mentioned in footnote 1, the private insurance market offers a single contract. He instead focuses on heterogeneous income, which naturally leads to the question of affordability, which we do not address. 
information is symmetric; (ii) no prioritisation exists in the public sector; and (iii) the PHI provides full insurance (coverage equals loss), which is natural in the context of symmetric information. In the same spirit as in the previous subsection, we analyse the worst-case scenario for the validity of our test, namely, a scenario where adverse selection is observed despite information being symmetric.

Unfortunately, the graphical analysis performed in the final wealths space becomes more complex than in previous sections. The reason is that there ceases to be a one-to-one relationship between each point in the final wealths space and each specific (premium, coverage) contract. In order to use the space of financial wealth in the case of heterogeneous losses, one must perform the same change of variable as in Section 1 (see subsection A.1 of the online Technical Appendix for details). Let subindex $J K$ denote an individual with probability $p_{J}=p_{H}, p_{L}$ of falling ill and severity given by loss $\ell_{K}=\ell_{H}, \ell_{L}$. The zero isoprofit line associated with attracting a type $J K=H H, H L, L H, L L$ can be expressed as

$$
a=\frac{w}{p_{J}}-\ell_{K}-n \frac{1-p_{J}}{p_{J}}
$$

Notice that, as usual, $\frac{d a}{d n}=-\frac{1-p_{J}}{p_{J}}$. More importantly, the point of no insurance (either public or private) is type-dependent. Indeed, if $n=w$, then $a=w-\ell_{K}$. Hence $\mathbf{A}_{K}=\left(w, w-\ell_{K}\right)$. Notice that the points $\mathbf{A}_{H}$ and $\mathbf{A}_{L}$ correspond to the same (premium, coverage) contract, namely $(q, c)=(0,0)$. The same happens to any other contract $(q, c)$ : it leads to two different points in the wealth space, one for each severity-type. Importantly, if all types receive the same coverage $c_{P U B}$ in the public outside option (i.e. in the absence of prioritisation), this public option becomes $\mathbf{P}^{K}=\left(w, w-\ell_{K}+c_{P U B}\right)$, which again is type-dependent. Graphically, the vertical intercepts at $n=w$, denoted by $\mathbf{P}^{H}$ and $\mathbf{P}^{L}$ in Figure 4, have vertical coordinates given by

$$
a_{H}^{P U B}=w-\ell_{H}+c_{P U B}
$$


and

$$
a_{L}^{P U B}=w-\ell_{L}+c_{P U B}>a_{H}^{P U B}
$$

respectively. In Figure 4 we represent a situation where loss heterogeneity is so important that $H H$ individuals prefer to purchase PHI, whereas the $L L$ individuals prefer to take the public outside option. That is, we have adverse selection although information is symmetric. Indeed, the point $\mathbf{P}^{H}$ is less preferred by $H H$ to the PHI contract $\boldsymbol{\alpha}_{H H}^{*}$, whereas the point $\mathbf{P}^{L}$ is preferred to the PHI contract $\boldsymbol{\alpha}_{L L}^{*}$ by $L L$.

\section{[FIGURE 4 AROUND HERE]}

Intuitively, on the one hand, a higher loss implies a higher preference for the fullcoverage PHI. On the other hand, a higher loss also implies a higher premium (profits per capita are zero), which implies a higher preference for the free public option. The first effect is the more intense the further away from full insurance the public option is, since avoiding risk becomes more important. Now, if the high risk has a higher loss than the low risk while the two risks enjoy the same public coverage, it might be that only the high risk prefers the private option.

However, for this to be true the difference in loss between the two types must be large enough. One can in fact use Figure 4 to see this. Suppose that $\ell_{H}$ is sufficiently close to $\ell_{L}$ (in the current figure $\ell_{H}$ is much larger than $\ell_{L}$ ). Then the new position of point $\mathbf{P}^{H}=\left(w, w-\ell_{H}+c_{P U B}\right)$ would lie above the high risk indifference curve through the new position of $\boldsymbol{\alpha}_{H H}^{*}$. Hence the private sector would become inactive.

Note also, types $H L$ and $L H$ have to be considered. The former will choose the public option for two reasons: high premia in the PHI contract plus a low loss. The latter will choose the private option also for two reasons: low premia in the PHI contract and a high loss that will be fully covered there. Hence propitious selection should be observed if one restricts attention to these other two types.

To sum up, and in the same spirit as the previous subsection, one needs two conditions 
to be simultaneously satisfied in order to reverse the conclusions of Lemma 1. First, as argued, the differences in loss among individuals should be large enough. Second, the prevalence of types $\mathrm{HH}$ and LL should be large enough relative to types HL and LH.

It is important to bear in mind that this analysis lacks realism because we have ignored prioritisation of individuals in more severe condition in the public sector. Introducing this factor would complicate the model considerably, but our intuition is that prioritisation in public health care services would go in our favour, since prioritising individuals with larger losses would be similar to reducing the difference between losses.

\subsection{Differences with the Complements Framework}

As mentioned in the introduction, in some countries PHI is complementary to public health insurance (for instance, Medigap complements Medicare in the US). Using our notation, this means the following. The government commits beforehand to a specific level of loss reduction, say $\ell_{0}-\ell_{P U B}$, when the individual seeks care. If the individual has purchased PHI, upon seeking care he enjoys a further reduction in loss, say $\ell_{P U B}-\ell$, with $\ell<\ell_{P U B}<\ell_{0}$. This additional loss reduction, $\ell_{P U B}-\ell$, is borne by the private insurer. Importantly, this is unlike the substitutes framework, where the insurer bears the full cost of reducing the loss from $\ell_{0}$ to $\ell$.

As shown by Figure 5, this model is equivalent to the classic RS model except that isoprofits do not stem from point $\mathbf{A}=\left(w, w-\ell_{0}\right)$ (where the individual enjoys neither public nor private insurance) but from point $\mathbf{B}=\left(w, w-\ell_{P U B}\right)$, where the individual only enjoys public insurance (see subsection A.3 of the online Technical Appendix for details). The competitive equilibria under symmetric information and asymmetric information are depicted in Figure 5 by the pairs of points $\left(\boldsymbol{\alpha}_{L}^{*}, \boldsymbol{\alpha}_{H}^{*}\right)$ and $\left(\hat{\boldsymbol{\alpha}}_{L}, \boldsymbol{\alpha}_{H}^{*}\right)$, respectively. Notice that both types of individuals prefer to purchase PHI under both symmetric and asymmetric information. Indeed, under symmetric information point $\mathbf{B}$ is less preferred than $\boldsymbol{\alpha}_{J}^{*}$ by every type $J=L, H$, and under asymmetric information point $\mathbf{B}$ is less preferred than $\boldsymbol{\alpha}_{H}^{*}$ by type $H$ and less preferred than $\hat{\boldsymbol{\alpha}}_{L}$ by type $L$.

As a consequence, in order to obtain a test for asymmetric information under com- 
plementary PHI, one needs to observe the coverage enjoyed by each individual in his PHI contract. In this respect, the model predicts that under symmetric information all individuals take full coverage (selection into PHI is neither propitious nor adverse). If information is asymmetric the model predicts that low risks will enjoy lower coverage than high risks (selection into PHI is adverse). To sum up, one can implement an indirect test for asymmetric information analogous to the one we perform here, but data would have to include the level of coverage (see, for instance, Ettner, 1997).

[FIGURE 5 AROUND HERE]

\section{Testing for Adverse Selection}

The UK provides an ideal setting in which to apply and test our model. First, in the UK everyone is publicly insured through the NHS. The NHS is, in turn, financed through general taxation. Hence, individuals contribute to the financing of public care whether they use it or not. Second, some individuals buy PHI to obtain treatment from the private sector to avoid having to put up with long waiting lists in the NHS. Health care obtained through PHI also offers better hospital amenities (private room, en-suite rooms, etc.). Hence, public insurance and PHI coexist in our setting.

According to our theoretical model (Corollary 1), if information is symmetric then propitious selection should be observed (the innate probability of seeking medical care for the privately insured is lower than the average in the population). Conversely, according to Corollary 2, if information is asymmetric then adverse selection should take place (the innate probability of seeking medical care for the privately insured is higher than the average in the population). In sum, our theoretical model predicts that in a substitutes framework, such as the UK, whether the distribution of information is symmetric or not has a dramatic effect on whether selection is adverse or propitious. Note that we refer to the innate probability of seeking care (instead of the narrower concept of probability of falling ill) because asymmetric information could be caused by heterogeneity in preferences for medical care (as we indicated in the theoretical model, there is also more on this below). 


\subsection{Institutional Setting}

PHI is relatively uncommon in Britain: the percentage of individuals with PHI has varied between 12\% and 13\% in the 1997-2007 period (Blackburn, 2008). The PHI market is usually divided into the individual market and the corporate market. In the individual market, customers buy insurance directly from the insurer or an insurance broker. In the corporate market, individuals obtain PHI from their employer. Though in some cases the employee has to contribute directly towards the cost of the premium, in $79 \%$ of cases the employee receives it free, as a fringe benefit. This corporate market is usually divided into the small corporation market (50 employees or fewer) and the large corporation market (more than 50 employees).

The regulation of the medical insurance industry is relatively soft in the UK. Before 2005, the industry was self-regulated with voluntary subscriptions to the General Insurance Standard Council, Financial Ombudsman, Personal Insurance Administration, and Association of British Insurers. Since 2005, the industry has been regulated by the Financial Services Authority (FSA, 2004). The regulation emphasises clarity and transparency of the products (Blackburn, 2008). Insurers use age, gender, smoking status, place of residence, and occupational status to set premiums (Foubister et al., 2006). Though insurers are free to base their premiums on any set of variables, health variables are generally not used for pricing (Mossialos and Thomson, 2004; Foubister et al., 2006). Instead of pricing existing illnesses, insurers exclude them from cover (exclusion of pre-existing conditions). In some insurance policies, the individual must disclose any pre-existing conditions at the time of buying the insurance and must grant access to his medical records to the insurer. In other insurance policies, disclosure of pre-existing conditions happens at the time of the claim. Any claim can be considered void if the insurer finds that the individual did not disclose all pre-existing conditions. This could contribute to alleviating the asymmetric information problem.

In general, PHI does not cover visits to the GP, accident and emergency admission, long-term chronic illnesses, or preventive treatment (Association of British Insurers, 2001). 
Insurers will typically not offer coverage to individuals older than 65 but existing policy holders are allowed to renew.

\subsection{The Data}

The data we use come from waves 6 to 18 of the British Household Panel Survey (BHPS) collected over the period 1996-2008. ${ }^{13}$ All adult members of each household are interviewed. Households are followed over time, even if the original household has split up. The BHPS oversamples residents in Scotland and Wales. We use sampling weights to make the sample representative of the non-immigrant population of Britain (we exclude Northern Ireland because it only enters the BHPS after the seventh wave). We only consider waves from the sixth onwards because that is when questions about PHI began to be included. We restrict our sample to male employees aged 23-59 (including females could lead to sample selection bias because a larger percentage of females do not work).

In our sample of male employees aged $23-59,5.6 \%$ buy PHI directly, $14.2 \%$ obtain PHI from their employer as a fringe benefit, 3.8\% obtain PHI from their employer but have the insurance premium deducted from their wages, $2.4 \%$ obtain PHI through a relative, and the remaining $74 \%$ do not have PHI.

\subsection{Test Rationale}

One would like to base the test for the type of selection (adverse or propitious) on a comparison of the innate probability of seeking medical care between those who decided to buy PHI and those who decided not to buy it. However, one does not observe the innate probability of seeking medical care, but rather whether an individual actually uses medical care. Hence, we use actual health care use as a proxy for innate probability of seeking medical care. Unfortunately, this test could overestimate adverse selection. Individuals with PHI might use health care services more often than individuals without

\footnotetext{
${ }^{13}$ The BHPS is produced by GfK NOP, the Office for National Statistics, and the Institute for Social and Economic Research (University of Essex), sponsored by the Economic and Social Research Council and supplied by the UK Data Archive. The Institute for Social and Economic Research is the copyright holder of the data. None of these is responsible for our analysis or interpretation of the data. See http://www.iser.essex.ac.uk/ulsc/bhps for more information.
} 
PHI because they enjoy better access conditions (e.g., less waiting time) and not because they have a higher innate probability of seeking medical care. This is the classical problem of distinguishing between moral hazard and adverse selection. Our strategy in this respect is described next.

Our test for adverse/propitious selection will compare the probability of using health care services for those who purchase PHI directly with that for those who receive it as a fringe benefit from their employer. Because these two groups enjoy PHI, differences in health care use cannot be due to differences in the coverage generosity (access conditions, waiting times, etc.) but are due to differences in the innate probability of seeking medical care. Our preferred variable to measure health care use is hospitalisation, though we also show results for GP services. However, note that GP services are not covered by PHI.

To be more precise, our test splits the population into two groups: those who must decide whether to buy PHI or not (or group D, for 'deciders') and those who receive PHI from their employer as a fringe benefit (or group N, for 'non deciders'). Our assumption is that, conditional on covariates and being employed, individuals who belong to the N-group have the same innate probability of seeking medical care as individuals who belong to the D-group. Group D can again be divided into two subgroups: those who purchase PHI (group DI) and those who do not (group DN). Since individuals in group D decide whether or not to buy PHI, their behaviour should follow our theoretical model. Consequently, if information is asymmetric then adverse selection should be observed (the probability of health care use in group DI should be higher than the population average, i.e. than in group N). Conversely, if information is symmetric, propitious selection should be observed (the probability of health care use in group DI should be lower than in group $\mathrm{N})$. Notice that if the difference in the probability of health care use between groups $\mathrm{N}$ and DI were not significantly different from zero then one could only conclude that the data are not informative enough to discern whether selection is adverse or propitious, and consequently whether information is symmetric or not. This is strikingly different from the tests performed under the complements or fully private framework, where a non- 
significant correlation between health care use and insurance coverage is taken as evidence of symmetric information.

Our testing strategy is subject to three validity threats: (1) the innate probability of seeking medical care of the N-group might be different from the D-group's; (2) N-group individuals receive more preventive care because their employers are especially conscious of their employees' health and hence they promote the take-up of preventive care by their employees; and (3) the coverage, and therefore the access conditions, provided by PHI contracts might be different between the N-group and the DI-group. We will address these concerns in subsection 3.6, after we have shown the results on the type of selection (adverse or propitious).

The regression models that we estimate control for age, age squared, smoking status, marital status, education, log-labour earnings, occupation, industry, plant size, pension offer, wave, region dummies, and a third-order polynomial in the number of months that have elapsed between the interview and 1 September of the year prior to the interview (see Table A1 in section $\mathrm{C}$ of the online Technical Appendix for the definitions of the variables). We use this last variable because individuals are asked about visits to the GP and hospitalisations since 1 September of the year previous to the interview, and consequently timing of the interview induces individual variation in the length of the reference period of health care use variables. The individual's occupation refers to whether it is managerial, professional, technical, clerical, and so on. Regarding industry variables, the BHPS uses the 1980 Standard Industrial Classification before the twelfth wave, and the 1992 Standard Industrial Classification from wave 12 onwards. ${ }^{14}$ Table A2 in section C of the online Technical Appendix provides the distribution of employer-provided PHI by occupation and industry. Note that a subset of the variables that we include in the regressions (age, occupation, smoking status, and place of residence) are used by insurers

\footnotetext{
${ }^{14}$ We use two sets of dummy variables for industry, one based on the 1980 classification and the other on the 1992 classification. The set of dummy variables based on the 1980 classification take the value 0 for all waves from the twelfth inclusive. The set of dummy variables based on the 1992 classification take the value 0 for all waves before the twelfth. This strategy minimises the possibility of bias at the expense of some efficiency loss.
} 
to set premiums. We do not include health variables because they are not used to price policies. $^{15}$

In our preferred specification, the sample is restricted to individuals that bought PHI directly and individuals that obtained PHI from their employer as a fringe benefit. However, in some regressions we include all male employees aged 23-59, and consequently we specify different dummy variables for individuals without PHI (DN-group), individuals with employer-provided PHI (N-group), individuals that obtain PHI through a relative and individuals that have their insurance premium deducted from their wages. The differences in the probability of hospitalisation are measured against the default category: those who bought PHI directly (DI-group).

We refrain from interpreting the results for those that have their insurance premium deducted from their wages because it is unclear how to classify such individuals. On the one hand, they can choose whether or not to buy PHI, and hence they could be classified as part of the group that buy PHI directly. On the other hand, their insurance premium might be particularly low because the purchase is arranged through their employer, and hence they could also be classified as part of the group that receives PHI as a fringe benefit. We also refrain from interpreting the results for individuals that obtain PHI through a relative (it is again unclear how to classify them, but note in any case that only $2.4 \%$ individuals in the sample are of this status).

\subsection{Test Results}

Table 1 reports differences in the conditional probability of using several types of health care (hospitalisation, GP visit, and preventive tests) estimated using Probit models. Panel A restricts the sample to our main groups of interest: N and DI individuals. First, we focus on column 1, which includes all of the control variables mentioned above.

\footnotetext{
${ }^{15}$ Only in 2003, the second largest health insurance company in the UK started to use weight and height when setting the premiums in some of its policies (Foubister et al., 2006; Blackburn, 2008). However, this appears to have been discontinued since at least November 2009 (they were not available on the company's website in November 2009). In general, individual underwriting has not been widely developed (Blackburn, 2008). In any case, we obtain qualitatively similar results when we restrict our sample to before 2003; results are available from the authors upon request.
} 
Column 1 shows that DI-group individuals are more likely to be hospitalised than Ngroup individuals, which is consistent with adverse selection. Specifically, individuals with employer-provided PHI are 2.9 percentage points less likely to have any hospitalisation (with respect to the group who bought PHI directly). This is a very sizeable difference (4.9\% of individuals in the sample have been hospitalised in the reference period) that is very precisely estimated (statistically significant at the $1 \%$ level).

\section{[TABLE 1 AROUND HERE]}

Panel B of Table 1 shows estimated differences in health care use when we do not restrict the sample to the N- and DI-groups, but we also consider individuals that obtain PHI via a relative, those that have it deducted from their wage, and individuals without PHI. The estimates for individuals that have PHI deducted from their wages are negative but not significant, and they seem to be half way between the N-group and the DI-group. This seems to indicate that it is unclear whether to classify these individuals in the $\mathrm{N}$ - or in the D-group, as our discussion above anticipated.

Comparing the $\mathrm{N}$ - and DN-group hospitalisation rates can help us to provide evidence in favour of our main assumption: individuals who belong to the N-group have the same innate probability of seeking medical care as individuals who belong to the D-group. To show evidence on this, we will exploit that the DN group is the vast majority, $84 \%$, of the D-group. So, one would expect the hospitalisation rates of N-group individuals to be larger but similar to those of DN-group individuals if the following three conditions hold - adverse selection, absence of moral hazard in hospitalisation, and the N-group is a random draw from the population (union of $\mathrm{D}$ and $\mathrm{N}$ group). Our result in Table 1 is consistent with this. The first and fourth rows of column 1 in Panel B show (indirectly) that DN- and N-group individuals have the same hospitalisation rates (because both are the same relative to the DI-group rates: 2.4 percentage points less).

We recognize that an alternative set of conditions could explain these results: moral hazard in hospitalisation is present, and N-group individuals are particularly healthy. Our results from Tables 2 and 4 will rule out this alternative explanation. We also note that the 
absence of moral hazard in hospitalizations is in line with the well-known Rand Health Insurance Experiment, which did not find evidence of moral hazard in hospitalisation (Manning et al. 1987).

Panel B of Table 1 also shows that DN individuals are less likely to be hospitalised than DI (2.4 percentage points according to column 1). Under the hypothesis of absence of moral hazard in hospitalisation, this difference is also indicative of adverse selection (note that N-group individuals' health status is irrelevant in this comparison).

Regarding GP services, individuals with employer-provided PHI are less likely to have seen the GP than individuals that bought PHI directly, though the difference is only statistically significant at conventional levels in panel A of Table 1. This difference is also consistent with the existence of adverse selection. Columns 7-9 on preventive tests will be useful below (subsection 3.6.2).

\subsection{What Is the Source of Asymmetric Information?}

As mentioned in Section 1, the theoretical model is agnostic as to why the innate probability of seeking medical care is heterogeneous across individuals. The heterogeneity in probabilities of health care use could come from differences in underlying health and/or from differences in tastes that yield heterogeneity in the propensity to seek medical care for a given level of health. Next, we examine this issue and try to determine the source of heterogeneity in the probability of health care use that we found in Table 1. To do this, we will use information on the number of health problems that the individual declares to suffer from, as well as 'on the importance given to health' by the individual, which we see as related to the individual's preference for health and health care use.

Table 2 shows that there are no statistically significant differences in the probability of suffering from at least one health problem (columns 1-3) or in the number of health problems (columns 4-6) across insurance groups. ${ }^{16}$ In particular, there are no differences

\footnotetext{
${ }^{16}$ The respondent is given a list of health problems and must indicate which ones he is suffering from. The list includes problems with arms or legs, difficulty seeing or hearing, skin conditions, asthma or bronchitis, cardiovascular problems, problems with the stomach, liver or kidnies; diabetes, anxiety or depression, alcohol or drug problems, epilepsy, migraine or frequent headaches, cancer; stroke, and other.
} 
between the health problems suffered by those without PHI and those that buy it directly in the market (Table A3 in section C of the online Technical Appendix shows that both of our health problem variables are very strongly correlated with health care use and income). The point estimates are very close to zero, and the sizes of the confidence intervals are reasonably small. Hence, it seems unlikely that the evidence of adverse selection that Table 1 showed is due to differences in health status. In this regard, it seems that the common practice by insurers of excluding pre-existing health conditions from coverage, and/or the variables used to price the insurance contracts, are working well and prevent adverse selection due to health status.

\section{[TABLE 2 AROUND HERE]}

A much more complicated task for insurers would be to measure/observe individuals' preferences for health care, which could then be the source of asymmetric information. In fact, attitudes towards medical care, beliefs about treatment efficacy, perceptions about illness, and fear and concern about medical treatment are factors used in psychology to explain health care use (Andersen and Newman, 1973; Kirscht, 1983; Edelmann, 2000). ${ }^{17}$ We use whether or not the individual says that health is very important for him to shed light on this issue. We think of this variable as being directly related to the individual's attitude towards health and indirectly to his attitude towards medical treatment. For instance, we would think that individuals who give more importance to their health will be less likely to adopt a 'wait and see' strategy when they start suffering from an illness symptom. Column 1 of Table 3 (Panel B) shows that individuals who bought PHI directly in the market are more likely to answer that health is very important for them than individuals with employer-provided PHI(6.3 percentage points difference) and than individuals without PHI (9.3 percentage points difference). Admittedly, some of the results are only significant at the $10 \%$ level, but this is because the health importance

\footnotetext{
${ }^{17}$ Quoting Edelmann (2000) 'Indeed, there is wide individual variation in the tendency to seek formal health care, some people being more inclined to adopt a "wait and see" strategy, while others seek care on a regular basis without there being any evident pathology to explain the symptoms'. It is illustrative to consider the extremes: blood-injury phobia that delays and/or causes medical care avoidance, and abnormal illness behaviour (including hypochondriacal concerns) that causes excessive health care use.
} 
question is only available in waves 8 and 13 so the sample size is much smaller than in Table 1 (4, 534 observations in Table 3 vs. 30,501 in Table 1$)$.

Columns 3-6 of Table 3 show that the probability of hospitalisation is higher for individuals who responded that health was very important for them (this is mostly obvious from estimates in Panel B, which includes all insurance groups in the sample; note that the sample size is much smaller in Panel A) ${ }^{18}$ Columns 7-10 report the results for any visit to the GP, which is also positively correlated with the importance attributed to health but is only statistically significant, at the $10 \%$ level, when we use visits to the GP in the following wave (we use the following wave to minimize the risk that it is health care use that is affecting the importance attributed to health by the individual).

\section{[TABLE 3 AROUND HERE]}

To sum up, individuals who respond that health is very important for them are more likely to use health care services, and are also more likely to have bought PHI directly in the market. This implies that the variable 'importance given to health', which is likely to reflect preferences for health as well as health care use, might be a source of asymmetric information and might be causing part of the observed adverse selection

\subsection{Threats to Validity}

\subsubsection{Representativeness of the comparison group}

We use the panel structure of our data to provide evidence in favour of our key assumption: individuals who belong to the N-group have the same innate probability of seeking medical care as individuals who belong to the D-group. ${ }^{19}$ For that purpose, we compare the health care use and health status between $\mathrm{D}$ - and N-group individuals. It is important to take into account that moral hazard might complicate the comparison, as all N-group individuals enjoy better access conditions to hospitalisations than DN-group individuals. This problem is alleviated if, for N-group individuals, we use only those

\footnotetext{
${ }^{18}$ We believe that it is legitimate to include individuals in all insurance groups because the variable of interest (importance attributed to health) is related to preferences directly.

${ }^{19}$ A similar assumption to ours has been maintained by Ettner (1997) and Cardon and Hendel (2001) for the US where employer-provided PHI plays a much more important role than in the UK.
} 
observations before they got employer-provided PHI. The reason is that, at that point, only a minority of them would have PHI (which was directly bought by them). ${ }^{20}$ The top panel of Table 4 shows that the health care use and health status of individuals who will go on to having employer-provided PHI in the future is not statistically different from that of individuals who will never have employer-provided PHI. The standard errors are similar to those in Tables 1 and 2, but the point estimates are much smaller. In particular, the point estimates for hospitalisations (our preferred measure) are very close to zero. Overall, there is no indication that those who will have employer-provided PHI in the future used health care services less than D-group individuals.

\section{[TABLE 4 AROUND HERE]}

As we saw in Panel B of Table 1, whether moral hazard is present or not is important for the interpretation of some of our results. To shed light on this, panel B of Table 4 shows the same comparison as in panel A but after N-group individuals have obtained employer-provided PHI. Consequently, moral hazard could potentially play an important role in this comparison because all $\mathrm{N}$ individuals have employer-provided PHI. However, we find that the differences in hospitalisation rates between D-group individuals and Ngroup individuals are also very small and not statistically different from zero. There are no statistically significant differences in visits to the GP or health status either. The fact that the differences in hospitalisation rates in panel B are very similar to those in panel A provide further evidence of the absence of moral hazard in hospitalisations (which was one of the assumptions that we used to interpret the findings of Table 1, panel B). Taken together, the results from both panels of Table 4 provide support to our main assumption that N-group individuals have the same innate probability of seeking medical care as individuals who belong to the D-group. ${ }^{21}$

\footnotetext{
${ }^{20}$ In this case, the percentage of individuals with PHI (directly purchased) in the N-group (D-group) is $10.6 \%(5.9 \%)$. This difference is not large enough for moral hazard to confound the interpretation of the comparison in practice. This is partly because moral hazard effects tend to be either small or moderate. A back-of-the-envelope calculation shows very clearly that moral hazard is unlikely to be a problem. In the RAND Health Insurance Experiment, the difference in the probability of hospitalisation between the free health care plan and the $95 \%$ cost-sharing plan was 0.024 , which when multiplied by 0.047 gives an approximate difference of 0.001 in the probability of hospitalisation due to moral hazard.

${ }^{21}$ The results in Panel B of Table 4 were to be expected given the results shown in Panel B of Tables 1
} 
We further provide evidence on the representativeness of our comparison group by testing the sensitivity of our estimates to the exclusion of several covariates. Our key assumption might be violated if fringe benefits are positively correlated with productivity, which might be related to health. Note that this is not necessarily a problem for our empirical strategy because (1) asymmetric information does not seem to be caused by health but by heterogeneity in preferences related to health care use and (2) we control for individual labour earnings which will be strongly correlated with individual productivity. To investigate how sensitive our estimates are to the omission of worker productivity, we estimate models of health care use in which we purposefully omit variables that are almost surely correlated with worker productivity. In columns 2-3 and 5-6 of Table 1, we report estimates that exclude some of the control variables that we used in our preferred specifications (columns 1 and 4) such as industry and occupation, plant size, earnings, smoking status, and education. The differences in the probability of health care use hardly change at all when we omit these important variables (especially in Panel A which focuses on the sample we are most interested in). Note that this strategy only provides valuable information if some of the excluded variables are correlated with having employer-provided PHI. According to Table 5, while education is not conditionally correlated with having employer-provided PHI, labour market variables such as industry, occupation, plant size and earnings are. However, as we have just seen, whether we include them or not in the regressions hardly makes any difference to our estimates of adverse selection (Table 1). The fact that we obtain the same results independently of whether or not we include earnings and job characteristics (industry, occupation, pension offer, and plant size) in the regressions of Table 1 seems to confirm that the asymmetric information is not the result of health status heterogeneity (which is correlated with earnings, as Table A3 in section $\mathrm{C}$ of the online Technical Appendix C indicates) but of heterogeneity in the preferences for health and health care.

and 2. The main difference is that in Tables 1 and 2 we compare the $\mathrm{N}$ group with the DN and DI groups separately, while we pool groups DN and DI in Table 4. Since group DN is much larger than group DI, the coefficients in Panel B of Table 4 are similar to the difference between the coefficients associated to group $\mathrm{N}$ and the coefficients associated to DN in Tables 1 and 2. 


\section{[TABLE 5 AROUND HERE]}

Another possible source of bias in our comparison could be that employees with worse health status sought out jobs offering employer-provided PHI. If this bias were present, it would go in our favour in the sense that would be underestimating the extent of adverse selection (see also Ettner 1997).

\subsubsection{Differences in preventive effort}

A legitimate concern would be that firms that offer PHI as a fringe benefit also promote the take-up of preventive health care services, which might result in a lower hospitalisation probability for individuals with employer-provided PHI. Columns 7-9 of Table 1 show differences in the probability that an individual took at least one preventive test in the last year. Overall, the results show no differences in the use of preventive tests between individuals with employer-provided PHI and individuals who bought PHI directly in the market (the point estimates are close to zero and the confidence intervals are reasonably narrow).

\subsubsection{Differences in the coverage of the contracts}

Above we have found that group DI individuals use health care services more than group $\mathrm{N}$ individuals. This is consistent with adverse selection, but it is also consistent with a situation in which directly purchased policies are more generous than employerprovided policies (they could offer better access to health care). There are five reasons why we think that the latter does not hold. The first two rely on further empirical exploitation of our data, the third and fourth on theoretical grounds, and the fifth relies on existing empirical research on the PHI market in the UK. We now elaborate on these arguments in turn.

First, as mentioned above, our results show that individuals who bought PHI directly have a higher probability of using a GP (Table 1, Panel A, columns 4-6). Given that GP services are not covered by PHI, this difference should be due to underlying differences in the propensity to use health care services. 
Secondly, we exploit the fact that individuals with PHI are still eligible to be treated under the NHS to investigate whether they are treated under the NHS or under their PHI, which will depend on the benefits and costs of each option including the generosity of their private insurance coverage (Propper, 2000). According to Table 6, conditional on having a hospitalisation, individuals with employer-provided PHI are less likely than those with directly bought PHI to be treated under the NHS, though the difference is not statistically significant. $^{22}$ This result suggests that, if anything, employer-provided policies are more generous than directly bought ones. Admittedly, conditioning on hospitalisation raises the issue of sample selection bias, and hence the results must be interpreted with that in mind.

\section{[TABLE 6 AROUND HERE]}

Third, it is known that administrative costs per insurance policy are much higher in the individual market than in the corporate market. Hence, one would expect employerprovided PHI to be closer to full insurance than individually bought policies. A sufficient condition for this to be true is that the administrative load be proportional to the premium. Then, for the same level of coverage, the premium of the individual market insurance policy will be higher than the corporate market one.

Fourth, we know from our theoretical model that group DI individuals will obtain full insurance. The issue is whether group $\mathrm{N}$ individuals also obtain full insurance or not. The most straightforward theoretical analysis shows that they do. Indeed, suppose that we want to find the menu of contracts that maximises average employee welfare subject to (i) ensuring a fixed profit to the insurance company and (ii) keeping the risk mix in the firm fixed. It turns out that this menu reduces to a single (and therefore pooling) full-coverage contract. In other words, if employers do not use PHI to distort the risk mix, competition for workers will force employers to offer a full-coverage contract. Indeed, it is a widely supported view in the profession that employer provision of insurance solves the adverse selection problem directly, without needing to resort to reductions in coverage. ${ }^{23}$

\footnotetext{
${ }^{22}$ Because the sample size is small, we use a reduced number of control variables in this regression.

${ }^{23}$ Directly quoting Bhattacharya and Vogt (2006): 'For example, the leading health economics text says
} 
Fifth, Propper and Maynard (1989, p.11) study the most important features of the PHI in Britain. They claim that the benefits provided by corporate and individualpurchased PHI policies are very similar. This seems to remain true in most PHI policies but, in the mid-noughties, some small private insurers started to offer 'budget policies' that offered lower premiums and higher deductibles (Blackburn, 2008). These budget policies have been more popular in the individual market than in the corporate market. ${ }^{24}$ This would indicate that, if anything, deductibles tend to be higher in the individual than in the corporate market. ${ }^{25}$ We tend to think that deductibles will have little impact on hospitalisations, but if they have any it would mean that we are underestimating adverse selection.

\section{Conclusions}

Using a theoretical model of health insurance where a public and a private option coexist, we link whether information is symmetric or asymmetric with the type of selection observed in the market (propitious or adverse). In particular we have shown that if information is symmetric (asymmetric) then propitious (adverse) selection should be observed. Hence, one can indirectly test for the presence of informational asymmetries by empirically measuring the type of selection in a given PHI market. We have applied this to the UK, where the very important assumption that underlies our results is satisfied, namely the public option is financed through compulsory and general taxation and constitutes a substitutive option with respect to the private one. Since we find significant adverse selection, this leads us to conclude that informational asymmetries are indeed present in the UK's PHI market.

\footnotetext{
"group purchase by employers addresses the problem of adverse selection", (Folland et al., 2004). This sentiment is repeated in many places (Cutler, 2002; Gruber and Levitt, 2000; Buchmueller and DiNardo, 2002)'. This is corroborated by the fact that large group employer-provided insurance does not exclude pre-existing conditions.

${ }^{24}$ According to our conversations with market actors, the corporate market is more competitive and employers could keep premiums low by switching insurer. In contrast, switching costs are higher in the individual market, which means that individuals tend to switch to a budget policy within the same insurer when they need to reduce the cost of their PHI premium.

${ }^{25}$ Several industry sources have confirmed this to us though there are no available statistics on it. They claim that it is not in the interest of the employer for the employee to delay treatment.
} 
We have extended our analysis to cover cases with additional sources of heterogeneity. While some sources of heterogeneity reinforce our theoretical conclusions, others potentially go against them. We are confident about our main theoretical conclusions however, because several conditions would need to simultaneously hold in order to reverse them, and moreover there is evidence that some of these conditions do not hold in practice.

We test for adverse selection among male employees by comparing the use of hospital and GP services amongst those who receive PHI as a fringe benefit and those who buy it directly. We find strong evidence of adverse selection. When we investigate the source of adverse selection, we find that it is caused by differences in preferences rather than differences in underlying health. A possible explanation is that the practice by insurers of excluding pre-existing conditions (together with the variables that they use for pricing) is being successful at removing the asymmetric information in health status. However, it is intuitive that it will be much more difficult for insurers to eliminate the asymmetric information in preferences for health/medical care.

We rule out three alternative explanations of our results. First, our results are not due to the comparison group being healthier (conditional on covariates) than the general population. Second, we also rule out that our results are driven by differences in preventive effort. Third, we can also rule out that individually purchased contracts offer better coverage than employer-provided health insurance contracts.

Our finding that adverse selection is present in the UK PHI market is important for two reasons. First, the finding is a contribution in itself since recent empirical literature has found mixed support for this phenomenon in other markets. Second, it has at least two important implications: the risk mix that prevails in the publicly funded NHS, and therefore the costs borne by the government, greatly depend on whether selection into PHI is adverse or propitious. Moreover, since the presence of adverse selection allows us to infer that informational asymmetries exist, we can apply several results that are present in markets with such asymmetries. Namely, several authors have shown that if asymmetric information is present then one can increase welfare by appropriately imposing taxes on 
the contracts intended for the low risks while subsidising the contracts intended for the high risks (see Crocker and Snow, 1985; Olivella and Vera-Hernández, 2007).

Universitat Autónoma de Barcelona

University College London and Institute for Fiscal Studies

\section{REFERENCES}

Andersen, R. and Newman, F. (1973). 'Societal and individual determinants of medical care utilization in the United States', Milbank Memorial Fund Quarterly, Vol. 51, pp. 95-107.

Association of British Insurers. (2001). Are You Buying Private Medical Insurance? Take a Look at This Guide Before You Decide, London: ABI.

Besley, T. and Coate, S. (1991). 'Public provision of private goods and the redistribution of income', American Economic Review, Vol. 81, pp. 979-984.

Besley, T., Hall, J. and Preston, I. (1998). 'Private and public health insurance in the UK', European Economic Review, Vol. 42, pp. 491-497.

Besley, T., Hall, J. and Preston, I. (1999). 'The demand for private health insurance: do waiting lists matter?', Journal of Public Economics, Vol. 72, pp. 155-181.

Bhattacharya, J. and Vogt, W. B. (2006). 'Employment and adverse selection in health insurance', Working Paper 12430, National Bureau of Economic Research, August.

Blackburn, P. (2008). Health \& Care Cover. UK Market Report 2008 (fifth edition), London: Laing \& Buisson.

Blomqvist, A. and Johansson, P-O. (1997a). 'Economic efficiency and mixed public/private insurance', Journal of Public Economics, Vol. 66, pp. 505-516.

Blomqvist, A. and Johansson, P-O. (1997b). 'Rejoinder to T.M. Selden', Journal of Public Economics, Vol. 66, pp. 525-526.

Buchmueller, T. and DiNardo, J. (2002). 'Did community rating induce an adverse selection death spiral? Evidence from New York, Pennsylvania, and Connecticut', American Economic Review, Vol. 92, pp. 280-294.

Cardon, J.H. and Hendel, I. (2001). 'Asymmetric information in insurance: evidence from the National Medical Expenditure Survey', RAND Journal of Economics, Vol. 32, pp. 408-427.

Cawley, J. and Philipson, T. (1999). 'An empirical examination of information barriers to trade in insurance', American Economic Review, Vol. 90, pp. 827-846.

Chiappori, P.A. (2000). 'Econometric models of insurance under asymmetric information', In Handbook of Insurance, Huebner International Series on Risk, Insurance, and Economic Security, Boston, Dordrecht and London: Kluwer Academic.

Chiappori, P.A. and Salanié, B. (1997). 'Empirical contract theory: the case of insurance data', European Economic Review, Vol. 41, pp. 943-950. 
Chiappori, P.A. and Salanié, B. (2000). 'Testing for asymmetric information in insurance markets', Journal of Political Economy, Vol. 108, pp. 56-79.

Chiappori, P.A. and Salanié, B. (2003). 'Testing contract theory: a survey of some recent work', in (M. Dewatripont, L. Hansen and P. Turnovsky, eds), Advances in Economics and Econometrics - Theory and Applications, Eighth World Congress, Cambridge: Cambridge University Press (Econometric Society Monographs).

Crocker, K.J. and Snow, A. (1985). 'A simple tax structure for competitive equilibrium and redistribution in insurance markets with asymmetric information', Southern Economic Journal, Vol. 51, pp. 1142-1150.

Cutler, D. M.(2002) 'Health care and the public sector', in (A. J. Auerbach and M. Feldstein, eds.), Handbook of Public Economics,Vol. 4, pp. 2143-2243, Elsevier.

Cutler, D., Finkelstein, A. and McGarry, K. (2008). 'Preference heterogeneity and insurance markets: explaining the puzzle of insurance', American Economic Review, Vol. 98, pp. $157-62$.

Dahlby, B.G. (1981). 'Adverse selection and Pareto improvements through compulsory insurance', Public Choice, Vol. 37, pp. 547-558.

Edelmann, R. J. (2000). Psychological Aspects of the Health Care Process, Harlow: Prentice Hall.

Encinosa, W. (2003). 'The economics of crowd out under mixed public/private health insurance', Portuguese Economic Journal, Vol. 2, pp. 71-86.

Ettner, S.L. (1997). 'Adverse selection and the purchase of medigap insurance by the elderly', Journal of Health Economics, Vol. 16, pp. 543-562.

Fang, H., Keane, M. and Silverman, D. (2008). 'Sources of advantageous selection: evidence from the medigap insurance market', Journal of Political Economy, Vol. 116, pp. 303-350.

Finkelstein, A. (2004). 'Minimum standards, insurance regulation, and adverse selection: evidence from the medigap market', Journal of Public Economics, Vol. 88, pp. 25152547.

Finkelstein, A. and McGarry, K. (2006). 'Multiple dimensions of private information: evidence from the long-term care insurance market', American Economic Review, Vol. 96, 938-958.

Finkelstein, A. and Poterba, J. (2004). 'Adverse selection in insurance markets: policyholder evidence from the UK Annuity Market', Journal of Political Economy, Vol. 112, pp. 183-208.

Finkelstein, A. and Poterba, J. (2006). 'Testing for adverse selection with unused observables', Working Paper 12112. National Bureau of Economic Research.

Folland, S., Goodman, A. C. and Stano, M. (2004). Economics of Health and Medical Care, 4th edition, New York: Prentice Hall.

Foubister, T., Thomson, S., Mossialos, E. and McGuire, A. (2006). Private Medical Insurance in the United Kingdom, Copenhagen: European Observatory on Health Systems and Policies.

FSA (2004). Insurance Selling and Administration and Other Miscellaneous Amendments. Policy Statement 04/1, London: Financial Services Authority.

Gruber, J. and Levitt, L. (2000). 'Tax subsidies for health insurance: costs and benefits', 
Health Affairs, Vol. 19, pp. 72-85.

Hendel I. and Lizzeri, A. (2003). 'The role of commitment in dynamic contracts: evidence from life insurance', The Quarterly Journal of Economics, Vol. 118, pp. 299-327.

Kirscht, J.P. (1983). 'Preventive health behavior: a review of research and issues', Health Psychology, Vol. 2, pp. 277-301.

Manning, W.G., Newhouse, J. P., Duan, N., Keeler, E.B. and Leibowitz, A. (1987). 'Health insurance and the demand for medical care: evidence from a randomized experiment', The American Economic Review, Vol. 77, pp. 251-277.

Mossialos, E. and Thomson, S. (2004). Voluntary Health Insurance in the European Union, Copenhagen: World Health Organization.

OECD (2004). 'Proposal for a taxonomy of health insurance', Working Paper OECD Health Project, OECD.

Olivella, P. and Vera-Hernández, M. (2007). 'Competition among differentiated health plans under adverse selection', Journal of Health Economics, Vol. 26, pp. 233-250.

Propper, C. and Maynard, A. (1989). 'The market for private health care and the demand for private insurance in Britain', University of York, Centre for Health Economics, Discussion Paper 53, University of York.

Propper, C. (1989). 'An econometric analysis of the demand for private health insurance in England and Wales', Applied Economics, Vol. 21, pp. 777-792.

Propper, C. (1993). 'Constrained choice sets in the UK demand for private medical insurance', Journal of Public Economics, Vol. 51, pp. 287-307.

Propper, C. (1995). 'The disutility of time spent on NHS waiting lists', Journal of Human Resources, Vol. 30, pp. 677-701.

Propper, C. (2000). 'The Demand for private health care in the UK', Journal of Health Economics, Vol. 19, pp. 855-876.

Propper, C., Rees, H. and Green. K. (2001). 'The demand for private medical insurance in the UK: a cohort analysis', The Economic Journal, Vol. 111, pp. C180-C200.

Rees, R. and Wambach, A. (2008). 'The Microeconomics of insurance', Foundations and trends in Microeconomics, Vol. 4, pp. 1-163.

Rothschild, M. and Stiglitz, J.E. (1976). 'Equilibrium in competitive insurance markets: an essay on the economics of imperfect information', Quarterly Journal of Economics, Vol. 90, pp. 630-649.

Selden, T.M. (1993). 'Should the government provide catastrophic insurance?', Journal of Public Economics, Vol 51, pp. 241-247.

Selden, T.M. (1997). 'More on the economic efficiency of mixed public/private insurance', Journal of Public Economics, Vol 66, pp. 517-523.

Smart, M. (2000). 'Competitive insurance markets with two unobservables', International Economic Review, Vol. 41, pp. 153-169.

University of Essex. (2010). Institute for Social and Economic Research, British Household Panel Survey: Waves 1-18, 1991-2009 [computer file]. 7th Edition. Colchester, Essex: UK Data Archive [distributor], July, SN: 5151.

Villeneuve, B. (2003). 'Concurrence et antisélection multidimensionnelle en assurance', Annales d'Economie et Statistique, Num. 69, 119-142. 
Wambach, A. (2000). 'Introducing heterogeneity in the Rothschild-Stiglitz model', Journal of Risk and Insurance, Vol. 67, 579-592. 


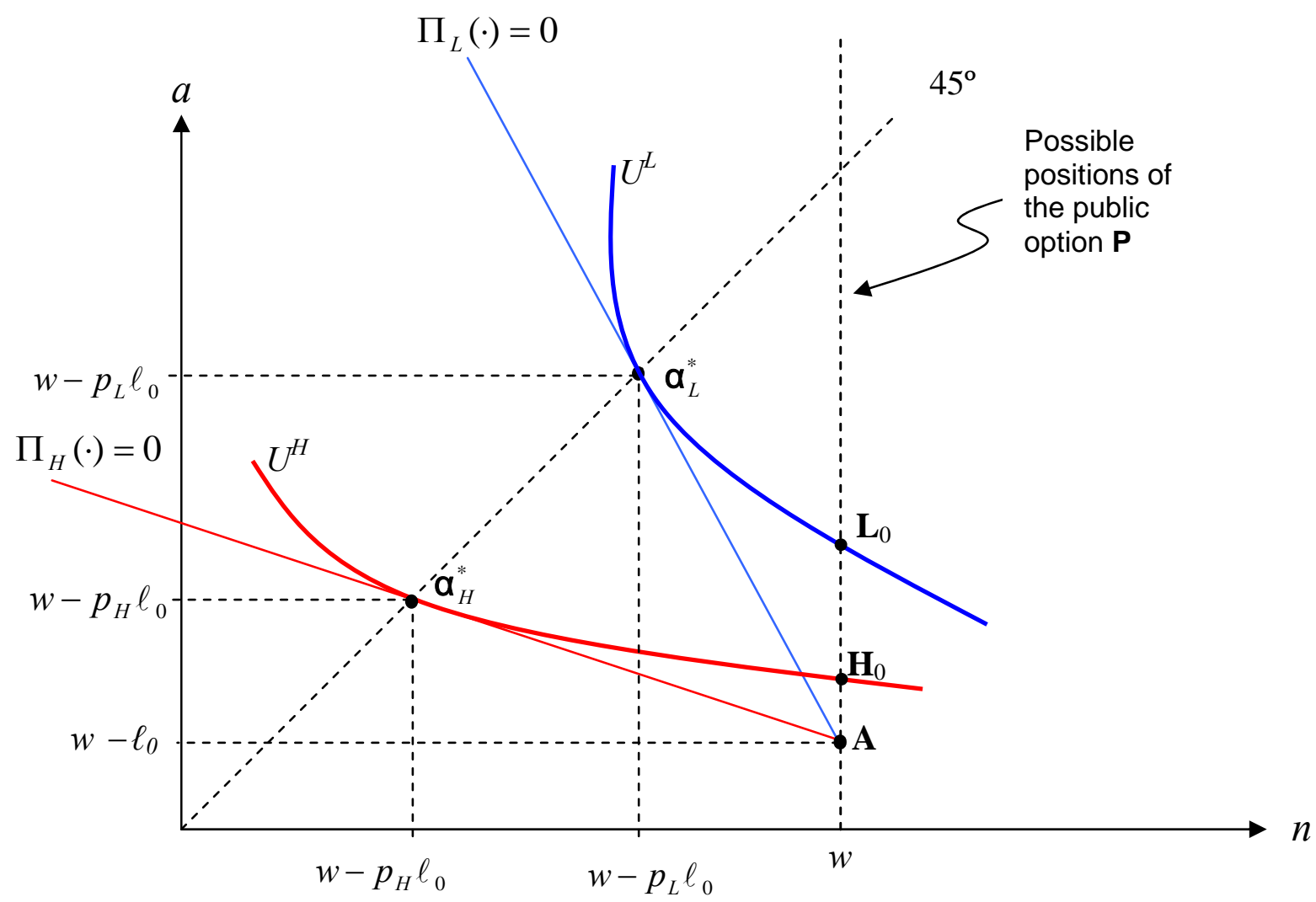

Fig. 1. The Equilibrium under Symmetric Information

Notes. The equilibrium pair of contracts in the absence of a public option is $\left(\boldsymbol{\alpha}_{L}^{*}, \boldsymbol{\alpha}_{H}^{*}\right)$, where, for each type, profits are zero and the isoprofit line is tangent to the indifference curve. Point $\mathbf{H}_{0}\left(\mathbf{L}_{0}\right)$ is the final wealth vector associated to the public option such that the high risk (low risk) is indifferent between sectors. The equilibrium set of active contracts depends on the position of the public option in the vertical line trough $w$. 


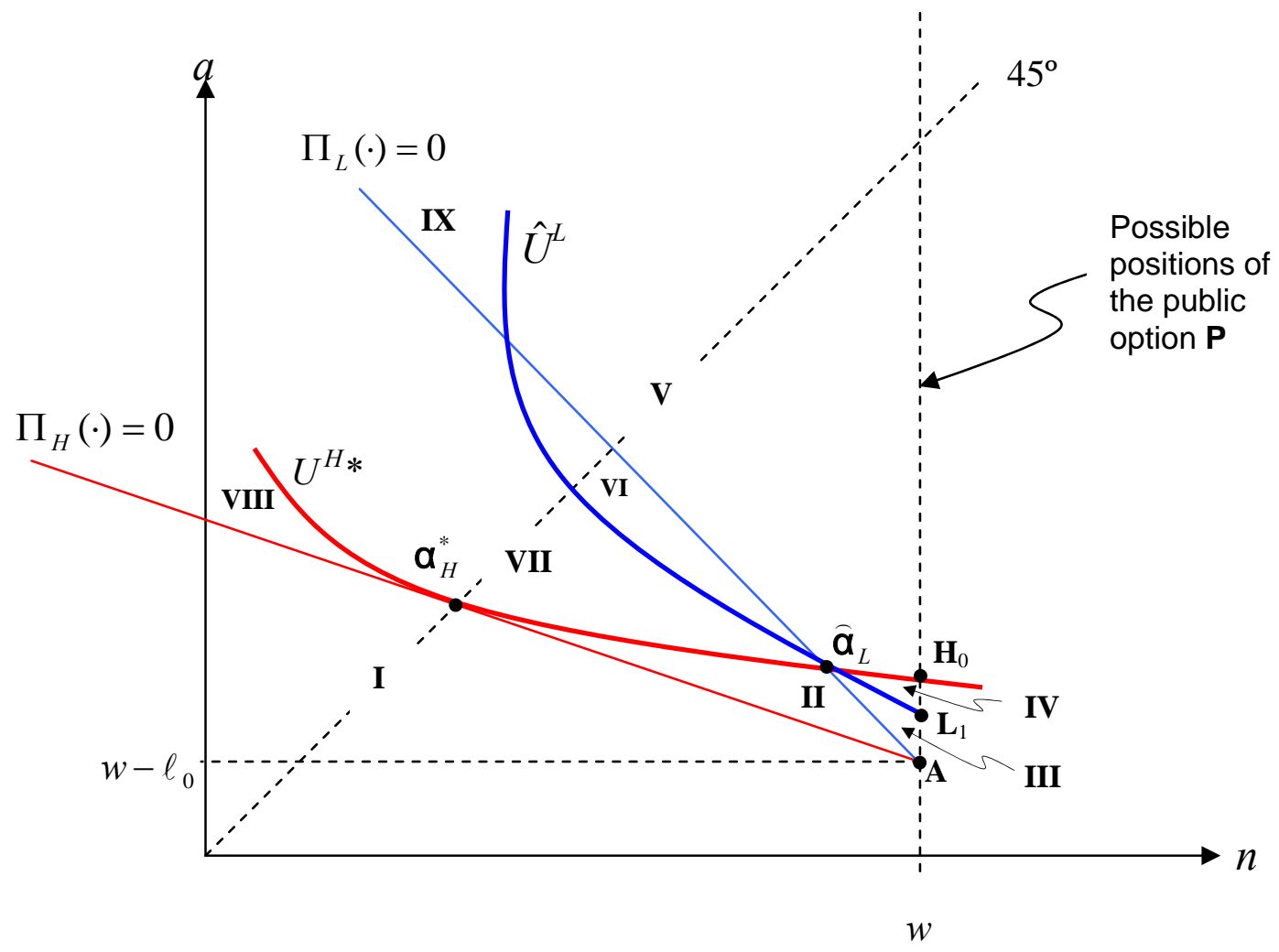

Fig. 2. The Equilibrium under Asymmetric Information

Notes. The equilibrium pair of contracts in the absence of a public option is $\left(\boldsymbol{\alpha}_{H}^{*}, \widehat{\boldsymbol{\alpha}}_{L}\right)$, where the high risk receives the same contract as under symmetric information, whereas the low risk receives a contract such that profits are zero and the high risk is indifferent between the two contracts. Point $\mathbf{H}_{0}$ is the same as under symmetric information. Point $\mathbf{L}_{l}$ is the final wealth vector associated to the public option such that the low risk is indifferent between sectors. The equilibrium set of active contracts depends on the position of the public option in the vertical line trough $w$. 


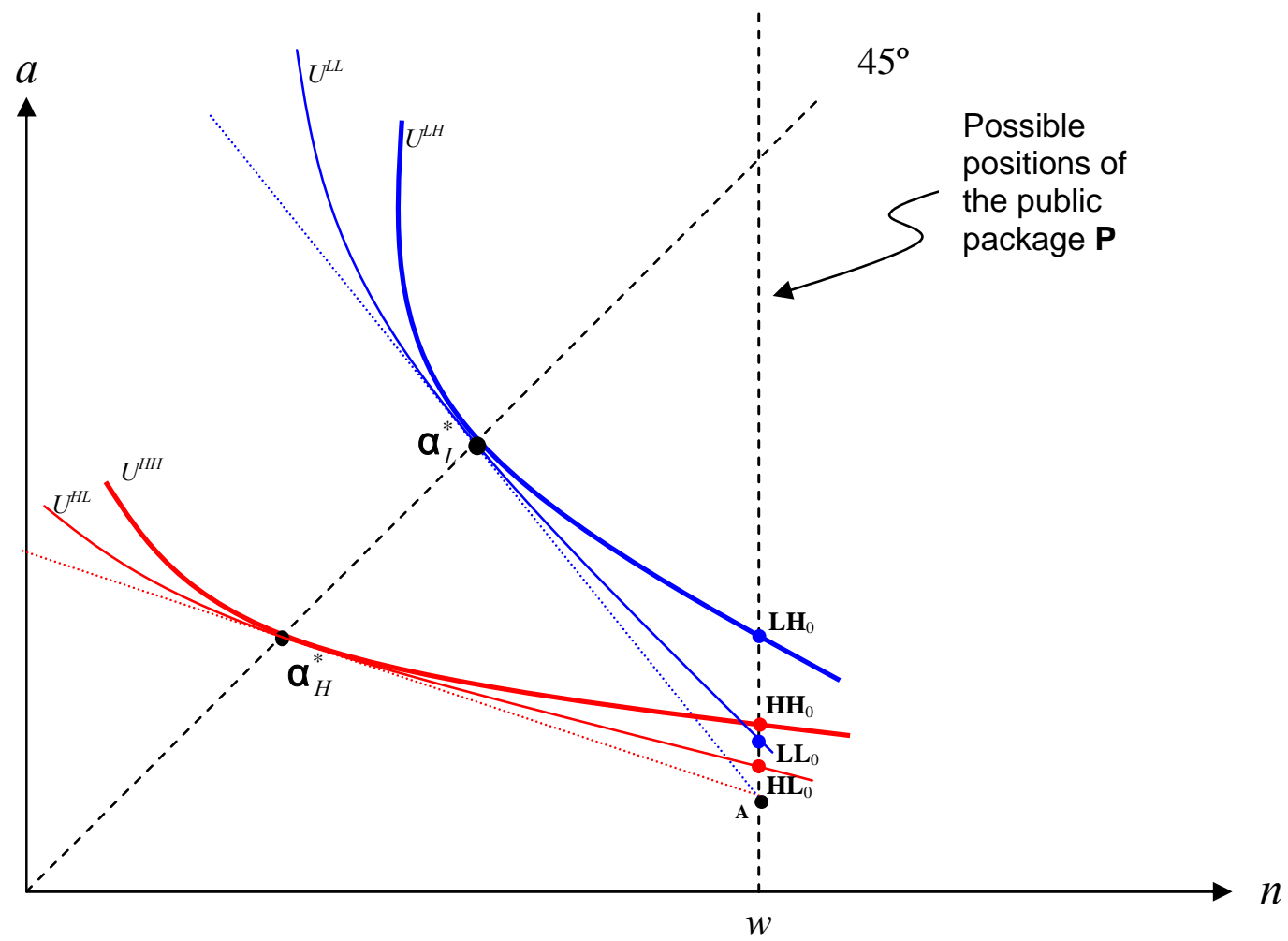

Fig. 3. Heterogeneous Risk Aversion

Notes. The equilibrium pair of contracts under symmetric information and in the absence of a public option is $\left(\boldsymbol{\alpha}_{L}^{*}, \boldsymbol{\alpha}_{H}^{*}\right)$, where subindices indicate risk, not risk aversion. They coincide with the equilibrium pair in Figure 1. Thicker indifference curves represent individuals with higher risk aversion. For $J=L, H$ and $K=L, H$, point $\mathbf{J K}_{0}$ is the final wealth vector associated to the public option such that type $J K$ (risk is $J$ and risk aversion is $K$ ) is indifferent between sectors. The roman numerals label regions used in the proofs. 


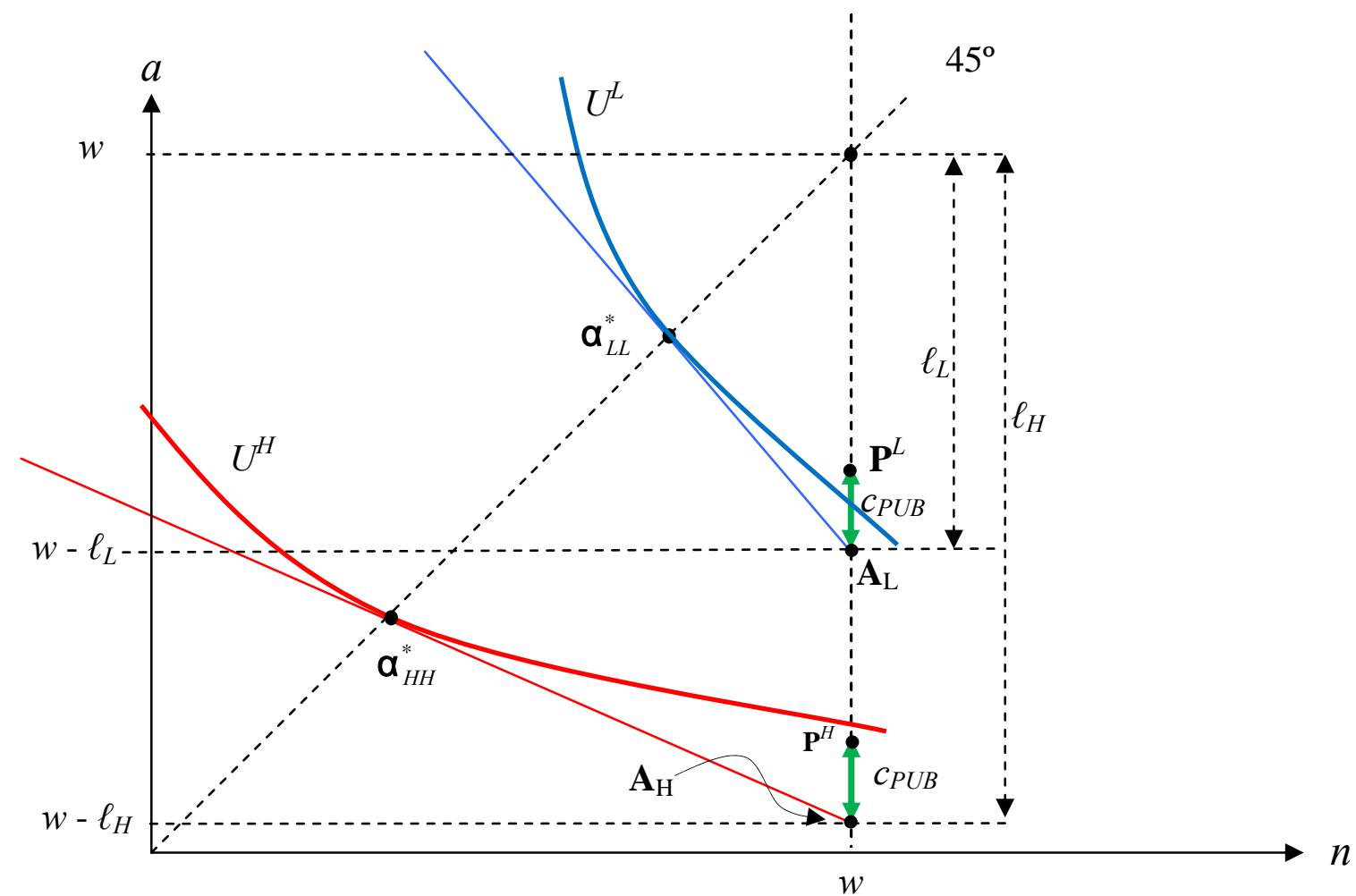

Fig. 4. Heterogeneous Losses

Notes. Here we consider only types $H H$ (high risk and high loss) and $L L$ (low risk and low loss). This implies that the high-loss no-insurance point is below the low-loss one. Losses are depicted by the two dashed vertical arrows $\ell_{L}$ and $\ell_{H}$. The equilibrium pair of contracts in the absence of a public option is $\left(\boldsymbol{\alpha}_{L L}^{*}, \boldsymbol{\alpha}_{H H}^{*}\right)$. Both yield zero profits and are efficient. We assume that all types receive the same coverage $c_{P U B}$ in the public option. We depict a specific public coverage in the figure by means of point $\mathbf{P}^{H}$ for type $H H$ and point $\mathbf{P}^{L}$ for type $L L$, which represent the respective final wealth vector. For this specific public coverage, the high risk prefers PHI whereas the low risk prefers the public option, hence selection is adverse. 


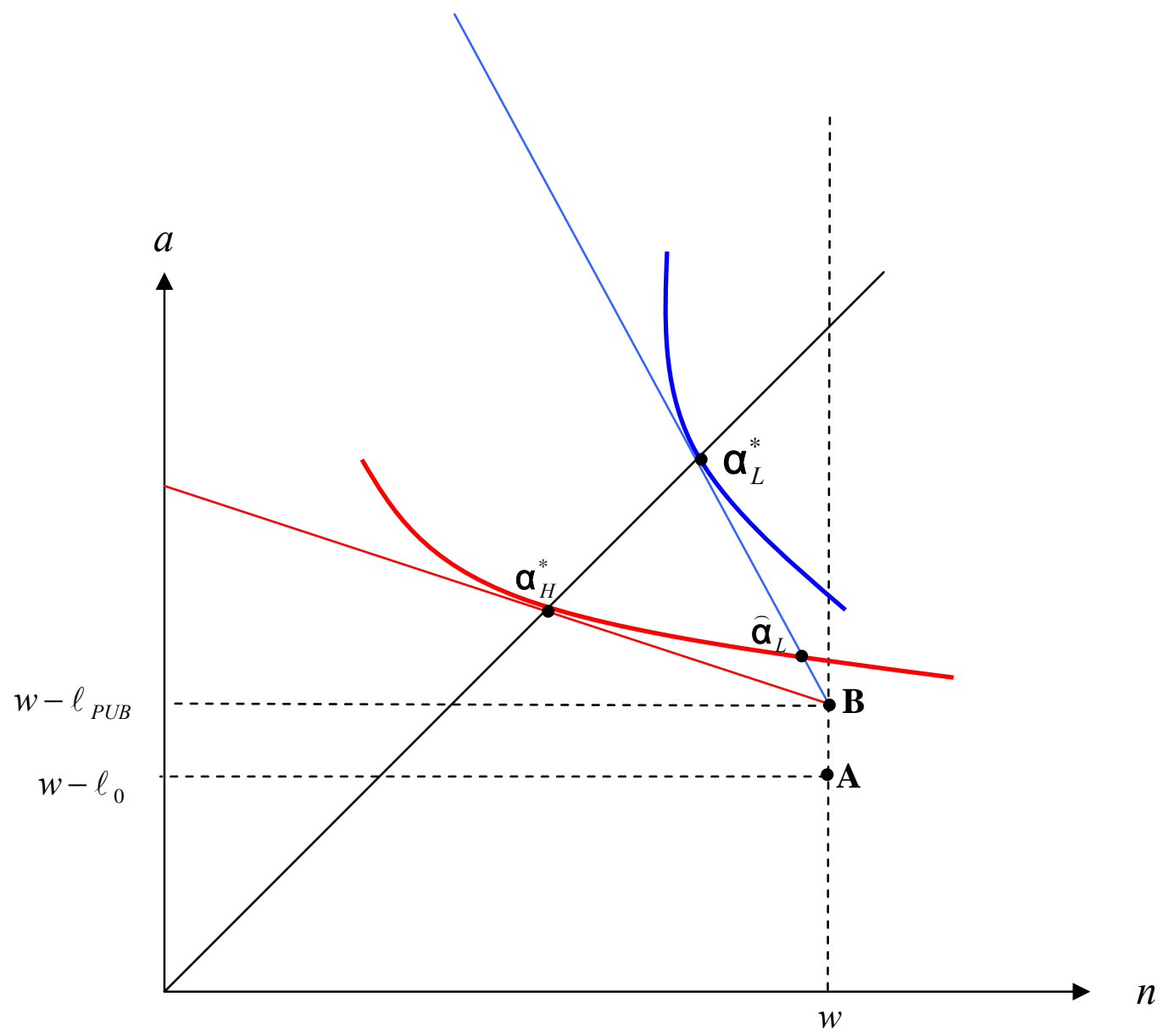

Fig. 5. Complementary Private Insurance

Notes. If PHI is complementary to the public one, isoprofits cease to stem from point $\mathbf{A}$, where the individual has neither public nor private insurance. Isoprofits instead stem from point $\mathbf{B}$, where the individual enjoys the public coverage. The equilibrium PHI contracts are derived and denoted as in Figures 1 (when information is symmetric) and 2 (when information is asymmetric). All individuals purchase PHI under every informational scenario. 
Table 1

Models of Health Care Use

(1) (2) (3) (4)

(5)

(6)

(7)

(8)

(9)

(Panel A) Sample: male employees aged 23-59 that have PHI either provided by employer or bought directly

PHI provided by employer (N-group)

\begin{tabular}{ccc}
\hline \multicolumn{3}{c}{ Dep. vble: Hospitalisation } \\
\hline$-0.029^{* * *}$ & $-0.026^{* *}$ & $-0.027^{* *}$ \\
{$[0.011]$} & {$[0.012]$} & {$[0.013]$}
\end{tabular}

\begin{tabular}{ccc}
\multicolumn{3}{c}{ Dep. vble: Any visit to the GP } \\
\hline$-0.046^{* *}$ & $-0.040^{*}$ & $-0.039^{*}$ \\
{$[0.022]$} & {$[0.022]$} & {$[0.021]$}
\end{tabular}

\begin{tabular}{|c|c|c|}
\hline \multicolumn{3}{|c|}{ Dep. vble: Any preventive test } \\
\hline-0.019 & -0.011 & 0.01 \\
\hline [0.014] & [0.014] & [0.014] \\
\hline
\end{tabular}

\begin{tabular}{ccc}
\hline & \multicolumn{3}{c}{ (Panel B) Sample: } \\
\hline \multicolumn{3}{c}{ Dep. vble: Hospitalisation } \\
\hline$-0.024^{* *}$ & $-0.026^{* *}$ & $-0.028^{* *}$ \\
{$[0.012]$} & {$[0.012]$} & {$[0.012]$} \\
-0.013 & -0.013 & -0.013 \\
{$[0.014]$} & {$[0.014]$} & {$[0.014]$} \\
-0.011 & -0.013 & -0.012 \\
{$[0.014]$} & {$[0.014]$} & {$[0.014]$} \\
$-0.024^{* *}$ & $-0.024^{* *}$ & $-0.022^{*}$ \\
{$[0.011]$} & {$[0.012]$} & {$[0.011]$}
\end{tabular}

\begin{tabular}{|c|c|c|}
\hline \multicolumn{3}{|c|}{ Dep. vble: Any visit to the GP } \\
\hline-0.015 & -0.03 & $-0.036 *$ \\
\hline$[0.021]$ & {$[0.021]$} & {$[0.021]$} \\
\hline
\end{tabular}

\section{tive of PHI}

$\mathrm{PHI}$ provided by employer (N-group)

\begin{tabular}{|c|c|c|}
\hline \multicolumn{3}{|c|}{ Dep. vble: Any preventive test } \\
\hline-0.016 & -0.012 & 0.006 \\
\hline [0.015] & [0.015] & {$[0.015]$} \\
\hline
\end{tabular}

PHI deducted from wages

$\mathrm{PHI}$ obtained through relative

$-0.009 \quad-0.012$

$-0.022$

$-0.019$

$-0.015$

$\left[\begin{array}{llllll}0.025 & {[0.025]} & {[0.026]} & {[0.018]} & {[0.019]} & {[0.018]}\end{array}\right.$

$-0.103 * * * \quad-0.104 * * * \quad-0.102 * * *$

$-0.011$

$-0.006$

$-0.011$

Without PHI (DN-group)

$\begin{array}{ccc}{[0.035]} & {[0.035]} & {[0.035]} \\ -0.051 * * * & -0.050 * * * & -0.047 * *\end{array}$

[0.023]

[0.023] [0.023]

[0.011]

[0.018]

[0.018] [0.018]

$-0.032 * *$

$-0.046 * * *$

\section{Controls (both panels)}

Industry and occupation

Plant size and pension offer

Earnings

Smoker

Education

$\begin{array}{lllllllll}\mathrm{Y} & \mathrm{N} & \mathrm{N} & \mathrm{Y} & \mathrm{N} & \mathrm{N} & \mathrm{Y} & \mathrm{N} & \mathrm{N} \\ \mathrm{Y} & \mathrm{N} & \mathrm{N} & \mathrm{Y} & \mathrm{N} & \mathrm{N} & \mathrm{Y} & \mathrm{N} & \mathrm{N} \\ \mathrm{Y} & \mathrm{Y} & \mathrm{N} & \mathrm{Y} & \mathrm{Y} & \mathrm{N} & \mathrm{Y} & \mathrm{Y} & \mathrm{N} \\ \mathrm{Y} & \mathrm{Y} & \mathrm{N} & \mathrm{Y} & \mathrm{Y} & \mathrm{N} & \mathrm{Y} & \mathrm{Y} & \mathrm{N} \\ \mathrm{Y} & \mathrm{Y} & \mathrm{N} & \mathrm{Y} & \mathrm{Y} & \mathrm{N} & \mathrm{Y} & \mathrm{Y} & \mathrm{N}\end{array}$

Notes. Marginal effects are shown with respect to the default category: directly bought PHI. Each column shows results from two Probit regressions with two different samples (as specified in the header of Panel A and Panel B) but with the same set of control variables (as specified in the bottom of the table). Control variables included in all regressions are: age, time elapsed, marital status, wave and region dummies. Sample sizes are 6,079 for Panel A regressions, and 30,501 for Panel B regressions. Standard errors are clustered at the individual level. ${ }^{* * *} p<0.01,{ }^{* *} p<0.05,{ }^{*} p<0.1$. 
Table 2

Models of Health Problems

$(1)$

(2)

(3)

(4)

(5)

(6)

(Panel A) Sample: male employees aged 23-59 that have PHI either provided by

PHI provided by employer ( $\mathrm{N}$-group)

Dep. vble: Any health problem

Dep. vble: Number of health problems

$\begin{array}{ccccccc}0.015 & 0.006 & -0.013 & & -0.008 & -0.016 & -0.052 \\ {[0.028]} & {[0.028]} & {[0.028]} & & {[0.060]} & {[0.062]} & {[0.058]}\end{array}$

(Panel B) Sample: male employees aged 23-59 irrespective of PHI

PHI provided by employer (N-group)

\begin{tabular}{ccccccc}
\hline \multicolumn{3}{c}{ Dep. vble: } & Any health problem & & \multicolumn{3}{c}{ Dep. vble: } & Number of health problems \\
\cline { 5 - 6 } \cline { 5 - 6 } 0.023 & 0.006 & -0.016 & & 0.024 & -0.003 & -0.05 \\
{$[0.027]$} & {$[0.027]$} & {$[0.027]$} & & {$[0.058]$} & {$[0.058]$} & {$[0.057]$} \\
-0.012 & -0.027 & -0.035 & & -0.001 & -0.025 & -0.043 \\
{$[0.030]$} & {$[0.030]$} & {$[0.030]$} & & {$[0.060]$} & {$[0.062]$} & {$[0.062]$} \\
-0.057 & -0.052 & -0.046 & & $-0.133 *$ & -0.118 & -0.106 \\
{$[0.040]$} & {$[0.040]$} & {$[0.041]$} & & {$[0.075]$} & {$[0.076]$} & {$[0.076]$} \\
-0.005 & 0.001 & 0.013 & & -0.033 & -0.016 & 0.008 \\
{$[0.023]$} & {$[0.023]$} & {$[0.023]$} & & {$[0.050]$} & {$[0.050]$} & {$[0.050]$}
\end{tabular}

\section{Controls (both panels)}

Industry and occupation

Plant size and pension offer

Earnings

Smoker

Education

$\begin{array}{ll}Y & N \\ Y & N \\ Y & Y \\ Y & Y \\ Y & Y\end{array}$

$\begin{array}{ll}N & Y \\ N & Y \\ N & Y \\ N & Y \\ N & Y\end{array}$

$\begin{array}{lll}Y & N & N \\ Y & N & N \\ Y & Y & N \\ Y & Y & N \\ Y & Y & N\end{array}$

Notes. Marginal effects are shown with respect to the default category: directly bought PHI. Each column shows results from either a Probit (columns. 1-3) or OLS regression (cols. 4-6) with two different samples (as specified in the header of Panel A and Panel B) but with the same set of control variables (as specified in the bottom of the table). Control variables included in all regressions are: age, time elapsed, marital status, wave and region dummies. Sample sizes are 6,079 for Panel A regressions and 30,496 for Panel B regressions. Standard errors are clustered at the individual level. ${ }^{* * *} p<0.01, * * p<0.05, * p<0.1$. 
Table 3

Importance of Health, Insurance, and Health Care Use

\begin{tabular}{|c|c|c|c|c|c|c|c|c|c|c|}
\hline & (1) & $(2)$ & (3) & (4) & (5) & (6) & (7) & (8) & (9) & $(10)$ \\
\hline & \multicolumn{10}{|c|}{ (Panel A) Sample: male employees aged 23-59 that have PHI either provided by employer or bought directly } \\
\hline & \multirow{2}{*}{\multicolumn{2}{|c|}{$\begin{array}{l}\text { Dep. var: Health is very } \\
\text { important for the } \\
\text { respondent }\end{array}$}} & \multicolumn{4}{|c|}{ Dependent var: Any hospitalisation } & \multicolumn{4}{|c|}{ Dependent var: Any visit to the GP } \\
\hline & & & $\begin{array}{c}\text { Current } \\
\text { wave hosp }\end{array}$ & $\begin{array}{c}\text { Current } \\
\text { wave hosp }\end{array}$ & $\begin{array}{c}\text { Next wave } \\
\text { hosp }\end{array}$ & $\begin{array}{c}\text { Next wave } \\
\text { hosp }\end{array}$ & $\begin{array}{c}\text { Current } \\
\text { wave visit }\end{array}$ & $\begin{array}{c}\text { Current } \\
\text { wave visit }\end{array}$ & $\begin{array}{c}\text { Next } \\
\text { wave visit }\end{array}$ & $\begin{array}{c}\text { Next } \\
\text { wave visit }\end{array}$ \\
\hline $\mathrm{PHI}$ provided by employer ( $\mathrm{N}$-group) & $\begin{array}{l}-0.067 \\
{[0.042]}\end{array}$ & $\begin{array}{l}-0.078^{*} \\
{[0.040]}\end{array}$ & & & & & & & & \\
\hline Health is very important for respondent & & & $\begin{array}{c}0.029 \\
{[0.027]}\end{array}$ & $\begin{array}{c}0.038 \\
{[0.025]}\end{array}$ & $\begin{array}{l}-0.005 \\
{[0.019]}\end{array}$ & $\begin{array}{l}-0.004 \\
{[0.019]}\end{array}$ & $\begin{array}{c}0.005 \\
{[0.039]}\end{array}$ & $\begin{array}{c}0.016 \\
{[0.040]}\end{array}$ & $\begin{array}{c}0.006 \\
{[0.043]}\end{array}$ & $\begin{array}{c}0.007 \\
{[0.044]}\end{array}$ \\
\hline \multirow[t]{4}{*}{ No. of observations } & 948 & 948 & 767 & 891 & 786 & 823 & 948 & 948 & 875 & 875 \\
\hline & \multicolumn{10}{|c|}{ (Panel B) Sample: male employees aged 23-59 irrespective of PHI } \\
\hline & \multirow{2}{*}{\multicolumn{2}{|c|}{$\begin{array}{l}\text { Dep. var: Health is very } \\
\text { important for the } \\
\text { respondent }\end{array}$}} & \multicolumn{4}{|c|}{ Dependent var: Any hospitalisation } & \multicolumn{4}{|c|}{ Dependent var: Any visit to the GP } \\
\hline & & & $\begin{array}{c}\text { Current } \\
\text { wave hosp }\end{array}$ & $\begin{array}{c}\text { Current } \\
\text { wave hosp }\end{array}$ & $\begin{array}{c}\text { Next wave } \\
\text { hosp }\end{array}$ & $\begin{array}{c}\text { Next wave } \\
\text { hosp }\end{array}$ & $\begin{array}{c}\text { Current } \\
\text { wave visit }\end{array}$ & $\begin{array}{c}\text { Current } \\
\text { wave visit }\end{array}$ & $\begin{array}{c}\text { Next } \\
\text { wave visit }\end{array}$ & $\begin{array}{c}\text { Next } \\
\text { wave visit }\end{array}$ \\
\hline PHI provided by employer ( $\mathrm{N}$-group) & $\begin{array}{l}-0.063^{*} \\
{[0.037]}\end{array}$ & $\begin{array}{c}-0.067^{*} \\
{[0.037]}\end{array}$ & & & & & & & & \\
\hline $\mathrm{PHI}$ deducted from wages & $\begin{array}{l}-0.023 \\
{[0.049]}\end{array}$ & $\begin{array}{l}-0.013 \\
{[0.047]}\end{array}$ & & & & & & & & \\
\hline $\mathrm{PHI}$ obtained through relative & $\begin{array}{l}-0.092 \\
{[0.056]}\end{array}$ & $\begin{array}{l}-0.089 \\
{[0.056]}\end{array}$ & & & & & & & & \\
\hline Without PHI (DN-group) & $\begin{array}{c}-0.093 * * * \\
{[0.031]}\end{array}$ & $\begin{array}{c}-0.097 * * * \\
{[0.032]}\end{array}$ & & & & & & & & \\
\hline Health is very important for respondent & & & $\begin{array}{c}0.019 * * \\
{[0.009]}\end{array}$ & $\begin{array}{c}0.020^{* *} \\
{[0.010]}\end{array}$ & $\begin{array}{c}0.025^{* * *} \\
{[0.010]}\end{array}$ & $\begin{array}{c}0.026 * * * \\
{[0.010]}\end{array}$ & $\begin{array}{c}0.012 \\
{[0.020]}\end{array}$ & $\begin{array}{c}0.012 \\
{[0.020]}\end{array}$ & $\begin{array}{l}0.035^{*} \\
{[0.021]}\end{array}$ & $\begin{array}{c}0.034 \\
{[0.021]}\end{array}$ \\
\hline No. of observations & 4,534 & 4,534 & 4,537 & 4,537 & 4,141 & 4,141 & 4,537 & 4,537 & 4,141 & 4,141 \\
\hline Controls (both panels) & & & & & & & & & & \\
\hline Industry and occupation & Y & $\mathrm{N}$ & Y & $\mathrm{N}$ & Y & $\mathrm{N}$ & Y & $\mathrm{N}$ & Y & $\mathrm{N}$ \\
\hline Plant size and pension offer & Y & N & $\mathrm{Y}$ & $\mathrm{N}$ & Y & $\mathrm{N}$ & $\mathrm{Y}$ & $\mathrm{N}$ & Y & $\mathrm{N}$ \\
\hline Earnings & $Y$ & $Y$ & $Y$ & Y & $Y$ & $\mathrm{Y}$ & Y & $Y$ & $Y$ & $\mathrm{Y}$ \\
\hline Smoker & Y & Y & Y & Y & Y & Y & Y & Y & Y & Y \\
\hline Education & $Y$ & $Y$ & $Y$ & $Y$ & $Y$ & $Y$ & $Y$ & $Y$ & $Y$ & $Y$ \\
\hline
\end{tabular}

Notes. Each column shows marginal effects computed from two Probit regressions with two different samples (as specified in the header of Panel A and Panel B) but with the same set of control variables (as specified in the bottom of the table). Columns 1 and 2 show marginal effects with respect to the default category: directly bought PHI. Control variables included in all regressions are: age, time elapsed, marital status, wave and region dummies. Standard errors are clustered at the individual level. ${ }^{* * *} p<0.01,{ }^{* *} p<0.05,{ }^{*} p<0.1$. 
Table 4

Testing the Representativiness of the Comparison Group

(1)

(Panel A) Sample: male employees aged 23-59 who belong to either the D-group, or the $\mathrm{N}$-group before

Will have employer-provided

Dep. vble: Hospitalisation

$\mathrm{PHI}$ in the future

$$
\text { Dep. vble: Any visit to }
$$

Dep. Vble: Any health

Dep. vble: Number

\begin{tabular}{cc}
\multicolumn{2}{c}{ the GP } \\
\hline-0.024 & -0.032 \\
{$[0.021]$} & {$[0.021]$}
\end{tabular}

problem

$\begin{array}{ll}-0.029 & -0.032 \\ {[0.028]} & {[0.028]}\end{array}$

health problems

$\begin{array}{ll}-0.015 & -0.026 \\ {[0.055]} & {[0.054]}\end{array}$

$[0.008]$

[0.008]

(Panel B) Sample: male emplo

Dep. vble: Hospitalisation

$\begin{array}{cc}-0.00004 & -0.002 \\ {[0.006]} & {[0.005]}\end{array}$

Dep. vble: Any visit to

\begin{tabular}{cc}
\multicolumn{2}{c}{ the GP } \\
\hline 0.024 & 0.01 \\
{$[0.017]$} & {$[0.016]$}
\end{tabular}

\section{Dep. Vble: Any health}

\begin{tabular}{cc}
\multicolumn{2}{c}{ problem } \\
\hline 0.025 & 0.001 \\
{$[0.022]$} & {$[0.022]$}
\end{tabular}

\begin{tabular}{cc}
\multicolumn{2}{c}{ Dep. Vble: Number } \\
health problems \\
\hline 0.056 & 0.01 \\
{$[0.044]$} & {$[0.042]$}
\end{tabular}

\section{Controls (both panels)}

Industry and occupation

Plant size and pension offer

Earnings

Smoker

Education

$\begin{array}{ll}Y & N \\ Y & N \\ Y & Y \\ Y & Y \\ Y & Y\end{array}$

$\begin{array}{llll}Y & N & Y & N \\ Y & N & Y & N \\ Y & Y & Y & Y \\ Y & Y & Y & Y \\ Y & Y & Y & Y\end{array}$

$\begin{array}{ll}N & Y \\ N & Y \\ Y & Y \\ Y & Y \\ Y & Y\end{array}$

$\begin{array}{ll}Y & N \\ Y & N \\ Y & Y \\ Y & Y \\ Y & Y\end{array}$

Notes. Each column shows marginal effects from two regressions with two different samples (as specified in the header of Panel A and Panel B) but with the same set of control variables (as specified in the bottom of the table). Probit models were used in columns 1-6 and OLS in columns 7 and 8 . Control variables included in all regressions are: age, time elapsed, marital status, wave and region dummies. Sample excludes individuals that have their PHI premium deducted from their wage, as well as individuals that obtain PHI through a relative. Sample size is 22466 for Panel A regressions, and 25011 for Panel B regressions. Standard errors are clustered at the individual level. ${ }^{* *} p<0.01,{ }^{* *} p<0.05,{ }^{*} p<0.1$. 
Table 5

Models of Having Employer-Provided PHI

\begin{tabular}{|c|c|c|c|}
\hline & $(1)$ & $(2)$ & (3) \\
\hline \multirow[t]{2}{*}{ Age (years) } & 0 & -0.001 & 0 \\
\hline & {$[0.001]$} & {$[0.001]$} & {$[0.001]$} \\
\hline \multirow[t]{2}{*}{ Married or cohabitating } & -0.011 & -0.008 & $0.032 * *$ \\
\hline & {$[0.012]$} & [0.014] & {$[0.014]$} \\
\hline \multirow[t]{2}{*}{ Less than O-levels } & -0.027 & -0.027 & 0.003 \\
\hline & [0.029] & [0.031] & {$[0.024]$} \\
\hline \multirow[t]{2}{*}{ O-levels } & 0.005 & 0.02 & $0.051 * *$ \\
\hline & {$[0.025]$} & [0.027] & {$[0.021]$} \\
\hline \multirow[t]{2}{*}{ A-levels } & 0.012 & 0.04 & $0.098 * * *$ \\
\hline & {$[0.026]$} & [0.029] & {$[0.024]$} \\
\hline \multirow[t]{2}{*}{ College } & 0.028 & $0.045^{*}$ & $0.138 * * *$ \\
\hline & {$[0.023]$} & {$[0.025]$} & [0.018] \\
\hline \multirow[t]{2}{*}{ More than college } & 0.018 & 0.004 & $0.160 * * *$ \\
\hline & {$[0.033]$} & [0.034] & {$[0.036]$} \\
\hline \multirow[t]{2}{*}{ Smoker } & $-0.040 * * *$ & $-0.045^{* * *}$ & \\
\hline & [0.012] & {$[0.013]$} & \\
\hline \multirow[t]{2}{*}{ LN of monthly earnings (2008 f) } & $0.151^{* * *}$ & $0.234^{* * *}$ & \\
\hline & {$[0.013]$} & {$[0.014]$} & \\
\hline \multicolumn{4}{|l|}{ P-Values of other controls } \\
\hline Industry & 0.000 & na & na \\
\hline Occupation & 0.000 & na & na \\
\hline Pension offer & 0.000 & na & na \\
\hline Plant size & 0.001 & na & na \\
\hline Pseudo-R squared & 0.28 & 0.15 & 0.05 \\
\hline
\end{tabular}

Notes. Marginal effects estimated through Probit models are shown. Sample includes male employees aged 23-59 that either have $\mathrm{PHI}$ provided by employer, bought it directly or do not have PHI (sample excludes individuals with $\mathrm{PHI}$ deducted through wages and individuals that obtain PHI through a relative). Cells are empty or labelled 'na' if the variable was not included in the regression. Other controls always included are wave and region dummies. Sample size is 28,581 . Standard errors are clustered at the individual level. $* * *$ $p<0.01, * * p<0.05, * p<0.1$. 
Table 6

Hospitalisation Funding Source (conditional on hospitalisation)

\begin{tabular}{lcccc}
\hline \hline & $\mathbf{( 1 )}$ & $\mathbf{( 2 )}$ & $\mathbf{( 3 )}$ & $\mathbf{( 4 )}$ \\
\hline & $\begin{array}{c}\text { NHS funded } \\
\text { hosp }\end{array}$ & $\begin{array}{c}\text { NHS partially } \\
\text { funded hosp }\end{array}$ & $\begin{array}{c}\text { NHS funded } \\
\text { hosp }\end{array}$ & $\begin{array}{c}\text { NHS partially } \\
\text { funded hosp }\end{array}$ \\
PHI provided by employer (N-group) & -0.103 & -0.051 & -0.089 & -0.033 \\
PHI deducted from wages & {$[0.085]$} & {$[0.083]$} & {$[0.088]$} & {$[0.090]$} \\
& 0.141 & 0.135 & & \\
PHI obtained through relative & {$[0.098]$} & {$[0.097]$} & & \\
& 0.075 & 0.045 & & \\
Without PHI (DN-group) & {$[0.099]$} & {$[0.098]$} & & \\
Sample size & $0.341 * * *$ & $0.312 * * *$ & & 297 \\
\hline \hline
\end{tabular}

Notes. Marginal effects (estimated using Probit regressions) are shown with respect to the default category: directly bought PHI. Sample in columns 1 and 2 includes male employees aged 23-59. Sample in columns 3 and 4 is the same as in columns 1 and 2 but excludes individuals with PHI deducted from wages, individuals that obtained $\mathrm{PHI}$ through a relative, and individuals without PHI. Control variables include: age, marital status, education, smoker, and LN(earnings). Standard errors are clustered the individual level. $* * * p<0.01, * * p<0.05$, $* \mathrm{p}<0.1$. 